\title{
O mercado brasileiro de vídeo: análise regulatória sob a perspectiva do direito norte-americano*
}

The Brazilian Video Marketplace: A Regulatory Analysis and Perspective under the US Law

\section{Resumo}

O presente estudo analisa o arcabouço regulatório em formação sobre distribuição de conteúdo eletrônico na indústria brasileira de telecomunicações. $\mathrm{O}$ artigo descreve 0 atual estágio da revolução mundial de convergência sob várias perspectivas e também como a rigidez de definições clássicas e de arcabouço regulatório de serviços de telecomunicações tradicionais tem postergado, ou mesmo colocado em risco, o avanço de mecanismos convergentes no Brasil. No contexto da revolução convergente, dá-se atenção especial aos conflitos entre radiodifusoras brasileiras e provedores de conteúdo via internet, bem assim como a legislação em elaboração os afetará. Finalmente, partindo-se do status questionis do debate no Brasil, o artigo analisa as propostas e consequências da normatização sobre controle de conteúdo eletrônico no país. Assim o faz em constante comparação entre os panos de fundo regulatórios do Brasil e dos Estados Unidos para embasamento de uma análise crítica e referencial.

\section{Abstract}

This work investigates the arising regulatory framework of electronic content distribution within the Brazilian Telecommunications Industry. The article describes the current stage of the convergence revolution in the world from diverse perspectives and how the rigidity of the classical definitions and the regulatory framework of traditional telecommunications services have delayed and even

*Tradução para a língua portuguesa do Grupo de Estudos em Direito das Telecomunicações da UnB (GETEL/UnB). Artigo derivado de dissertação de mestrado defendida no programa de pós-graduação da Faculdade de Direito da Columbia University.

"Mestre em direito (LL.M) pela Columbia University Law School, New York. Mestre em Direito e Políticas Públicas pelo Centro Universitário de Brasília (Uniceub). MBA em Gestão de Empresas pela Fundação Getúlio Vargas (FGV), e especialista em Direito da Regulação e da Concorrência pelo Uniceub. Membro da Associação Brasileira de Direito, Informática e Telecomunicações (ABDI). Trabalha no setor de telecomunicações desde 2001, inicialmente no escritório Pinheiro Neto Advogados e, após isso, na Consultoria SP Communications. 
endangered the advance of convergence tools in Brazil. In the context of the convergence revolution, special attention is paid to disputes between Brazilian broadcasters and Internet-based content providers and how the emerging legislation will affect them. Finally, from the current status questionis of the debate in Brazil, the paper analyzes the proposals and consequences of the electronic content control regulations in the country. This article constantly compares the Brazilian regulatory background with that of the United States for referential and critical analysis purposes.

Palavras-chave: conteúdo eletrônico; serviço de telecomunicações; controle de conteúdo; internet; Brasil; Estados Unidos.

Keywords: electronic content; telecommunications service; content control; Internet; Brazil; United States.

\section{Introdução}

O avanço tecnológico, em conjunto com a transmissão de conteúdo via ambiente computacional têm acelerado a chamada Era da Informação. Essa rápida transformação no modo como a sociedade lida com a notícia, os dados e o entretenimento redefine conceitos ultrapassados de plataformas de distribuição de informação, tornando essencial debruçar-se sobre o debate atual de reformulação regulatória dos serviços de telecomunicações e da internet frente à distribuição de conteúdo eletrônico.

Este artigo analisa o status atual e as tendências do conteúdo eletrônico brasileiro. Em acréscimo, este estudo analisa algumas estruturas regulatórias de telecomunicações no Brasil em comparação com as dos Estados Unidos. A escolha dos países não foi aleatória, pois as indústrias de informação eletrônica do Brasil e dos Estados Unidos eram consideravelmente parecidas no início do século XX, quando, a partir da década de 1960, passaram a seguir caminhos diferentes. É importante ressaltar que os Estados Unidos e o Brasil possuem mercados e nível de penetração de serviço para acesso a conteúdo eletrônico consideravelmente diferenciados, à exceção dos serviços de radiodifusão. De fato, basta um passar de olhos sobre o nível de penetração dos serviços de telecomunicações que contêm conteúdo eletrônico para chegar-se a esta conclusão (Tabela 1). 


\begin{tabular}{|l|c|c|}
\cline { 2 - 3 } \multicolumn{1}{c|}{} & Estados Unidos & Brasil \\
\hline Acessos banda larga à internet & $\begin{array}{c}107.434 .000 \\
(\text { maio de 2010) }\end{array}$ & $\begin{array}{c}30.600 .000 \\
\text { (setembro de 2010) }^{2}\end{array}$ \\
\hline Acessos à radiodifusão/residencial & $\begin{array}{c}114.907 .410 \\
\text { julho de 2010) }^{3}\end{array}$ & $\begin{array}{c}56.503 .090 \\
(\text { setembro de 2010) }\end{array}$ \\
\hline TV a cabo e por satélite & $\begin{array}{c}87.000 .000 \\
(\text { janeiro de 2010) }\end{array}$ & $\begin{array}{c}9.073 .817 \\
\text { (setembro de 2010) }^{6}\end{array}$ \\
\hline
\end{tabular}

Tabela 1 - Nível de penetração dos serviços de telecomunicações nos Estados Unidos e no Brasil

Para se alcançar o que foi proposto neste artigo, é necessário promover uma ampla revisão do conceito de convergência e de suas implicações e consequências para as plataformas e serviços de telecomunicações tradicionais. Sem uma avaliação das plataformas e serviços tradicionais, é impossível ter uma compreensão abrangente dos desafios regulatórios e das mudanças radicais no modelo de negócios dos serviços de distribuição de conteúdo eletrônico. $\mathrm{O}$ fenômeno da convergência, entretanto, tem muitas facetas, que exigem sejam abordados os diversos tipos de convergência para que se divise o impacto da revolução em andamento.

Ainda, o presente estudo parte de algumas definições atuais de serviços de telecomunicações e pondera os efeitos que a convergência lhes imprimiu. Nesse contexto, muitos dos serviços tradicionais de telecomunicações não têm sua identidade esclarecida tão somente por suas definições normativas. Esta é uma característica presente, em especial, nos serviços de distribuição de conteúdo eletrônico. Dessa forma, este estudo esforça-se em identificar características específicas de tais serviços, que vão além de suas definições e que podem ser utilizadas para propósitos variados.

\footnotetext{
${ }^{1}$ http://download.broadband.gov/plan/national-broadband-plan-chapter-3-currentstate-of-the-broadband-ecosystem.pdf. ${ }^{2}$ http://www.sinditelebrasil.org.br/noticia.php?id=170. Inclui acessos fixos e móveis de banda larga. ${ }^{3}$ http://www.fcc.gov/mb/video/tv.html. ${ }^{4}$ http://www.teleco.com.br/nrtv.asp. 5 http://www.ncta.com/Statistics.aspx. ${ }^{6}$ http://www.anatel.gov.br/Portal/exibirPortalNoticias.do?acao=carregaNoticia\&codi $\mathrm{g} 0=21463$.
} 
A terceira seção deste artigo apresenta uma avaliação das questões emergentes da batalha por controle sobre o conteúdo eletrônico no Brasil entre as radiodifusoras brasileiras e outros operadores de plataformas de conteúdo eletrônico, inclusive provedores de conteúdo via internet. Para uma análise mais aprofundada do conflito atual no Brasil, o artigo descreve sucintamente a história da indústria radiodifusora no país.

Em sequência, descreve-se a disciplina constitucional da indústria de conteúdo eletrônico no Brasil, em que as principais restrições constitucionais e seus efeitos sobre a distribuição de conteúdo eletrônico são identificados. O Projeto de Lei da Câmara (PLC) 116/2010, em tramitação no Senado Federal, originário do Projeto de Lei (PL) 29/2007, da Câmara dos Deputados, também é abordado. Caso o PLC 116/2010 seja aprovado, ele pode resultar em uma reviravolta no modelo regulatório brasileiro. As consequências para a internet podem ser significativas. Embora não haja expressa menção de que a internet esteja incluída no escopo do PLC 116/2010, ela também não é expressamente excluída dele. O artigo avalia os riscos da aplicação do PLC 116/2010 sobre o ambiente da internet. A proposta do PLC 116/2010 de sistema de cotas com base no conteúdo é analisada. $\mathrm{O}$ artigo concentra-se, todavia, na comparação abrangente entre os modelos constitucionais regulatórios do Brasil e dos Estados Unidos.

Após isso, o estudo identifica as características que fazem da radiodifusão algo distinto dos outros conteúdos distribuídos eletronicamente e de que modo elas se aplicam ao caso brasileiro, bem como analisa a justificativa apresentada para dita diferenciação de tratamento ou assimetria regulatória. Finalmente, examinam-se a importância da neutralidade de rede em meio ao conceito de diversidade, as interpretações deste conceito pelos reguladores brasileiros e a sua comparação com o conceito de neutralidade de rede adotado nos Estados Unidos.

O estudo busca analisar em que medida as transformações no cenário ambientador do arcabouço regulatório e legal de telecomunicações oriundas da convergência tecnológica devem resultar na reformulação integral da política setorial. O trabalho também busca avaliar em que medida todo conteúdo eletrônico deve obedecer a um mesmo conjunto de regras. Nesse contexto, a pergunta fundamental para análise consiste no seguinte: em que medida as radiodifusoras brasileiras (e as dos Estados Unidos) se diferenciam de outras mídias, nomeadamente TV a cabo, TV via satélite e Revista de Direito, Estado e Telecomunicações, v. 3, n. 1, p. 111-166 (2011) 
via internet, para justificar a continuidade de uma assimetria regulatória entre elas? Com o objetivo de responder a esta pergunta, o presente estudo examina se tais diferenças continuam existindo a despeito da convergência tecnológica.

\section{A revolução convergente}

\section{Convergência: à procura de uma definição}

Nesta seção, o trabalho aborda os desafios atualmente enfrentados pela indústria de distribuição de conteúdo $^{7}$ decorrentes do surgimento do fenômeno convergente. Aqui, são definidas a convergência tecnológica e a convergência no contexto brasileiro. O esforço de definição da convergência é mais do que uma indagação meramente teórica com implicações de ordem abstrata. Regulamentos, estruturas e sistemas jurídicos surgem de noções e valores que passam a interessar à sociedade. Se tais noções fundamentais mudam, com elas também são alterados os arcabouços legal e regulatório. É da maior importância definir-se e circunscrever-se o conceito de convergência em seus limites e características.

A definição de convergência deve incluir a consideração de seus efeitos não somente sobre os serviços de telecomunicações, mas também sobre o conteúdo da comunicação de massa. Além disso, é importante enfatizar que a convergência caminha para se configurar em um fenômeno mundial; ela não conhece fronteiras nacionais. Em uma economia globalizada de rápida expansão tecnológica, a mesma convergência é presenciada nos Estados Unidos e no Brasil quase que simultaneamente.

Encontrar uma definição de convergência é uma tarefa um tanto quanto desafiadora. Um das possíveis causas para dita dificuldade repousa na ideia de que hoje se vive dentro de uma bolha convergente ainda em expansão.

${ }^{7}$ Neste estudo, o termo conteúdo eletrônico é utilizado para se referir ao conteúdo
distribuído pela indústria de comunicação eletrônica de massa, tal como a
radiodifusão, TV a cabo, TV por satélite e via internet. Comunicações eletrônicas são
entendidas como a forma de comunicação que reúne três características básic as: a)
resultar de transmissão ou transporte; b) deter formato eletrônico, ou seja, resultar da
transformação de uma mensagem em sinais; c) ser constituída de sons, imagens e
dados. Esta definição é adotada por Paul Nihoul (2004). 
Nesse contexto, torna-se difícil ao observador afastar-se do objeto de pesquisa para vê-lo em sua totalidade. Isto também significa que existem consequências da convergência que ainda não foram reveladas.

De fato, a convergência é um termo de difícil precisão usado em vários contextos e frequentemente ambíguo em sua definição. ${ }^{8}$ As definições de convergência têm se tornado mais abrangentes com o decurso do tempo. Alguns pesquisadores parafraseiam o juiz Power Stuart, da Suprema Corte, em sua famosa referência ao significado de conteúdo indecente: "não posso defini-lo, mas sei quando o vejo"".

Um dos primeiros pesquisadores a procurar definir convergência foi Ithiel de Sola Pool. Em seu livro Technologies of Freedom, Pool identificou o que ele chamou de 'convergência de modos' [convergence of modes], que obscureceu as linhas limítrofes entre "mídias, mesmo entre comunicações ponto-a-ponto, como os correios, o telefone e o telégrafo, e a comunicação de massa, tais como a imprensa, o rádio e a televisão". ${ }^{10} \mathrm{Na}$ década de 1980 , Pool defendeu que um mesmo meio físico poderia transportar serviços que, no passado, eram providos por meios diferentes, ou seja, fios, cabos ou sinais eletromagnéticos.

Dois anos mais tarde, em 1985, Jonathan Levy e Peter Pitsch chamaram a atenção para o alto grau de fungibilidade que alguns tipos de mídias tinham. Em seu estudo, eles mostraram como o surgimento de novas tecnologias, como a TV a cabo ou a TV por satélite, apresentavam-se como substitutos perfeitos à radiodifusão de sons e imagens. ${ }^{11}$ Assim, o alto grau de fungibilidade entre os diversos serviços de telecomunicações antecipou os primeiros sinais do que viria a se tornar a convergência tecnológica.

Além disso, Henry Jenkins definiu convergência como "o fluxo de conteúdo em plataformas, a cooperação entre múltiplas indústrias de mídia e

${ }^{8}$ LAWSON-BORDERS, Gracie. (2005). Media Organizations and Convergence. Routhledge.

${ }^{9}$ Justice Potter Stewart, voto vencedor em Jacobellis v. Ohio 378 U.S. 184 (1964). ${ }^{10}$ POOL, Ithiel de Sola. (1983). Technologies of Freedom: On Free Speech on an Electronic Age . Cambridge, Massachusetts: Harvard University Press, p. 23.

${ }^{11}$ LEVY, Jonathan D.; PITSCH, Peter. (1985). Statistical Evidence of Substitutability Among Video Delivery Systems in Video Medias Competition, Regulations, Economics, and Technology. New York: Columbia University Press, p. 57.

Revista de Direito, Estado e Telecomunicações, v. 3, n. 1, p. 111-166 (2011)

DOI: https://doi.org/10.26512/lstr.v3i1.21669 
o comportamento migratório de audiências de mídia que se propõem a ir onde quer que seja à procura de outros tipos de entretenimento e experiências desejadas". ${ }^{12}$ Curiosamente, Jenkins argumentou que a convergência não teria ocorrido no momento em que os equipamentos de mídia convergiram. Pelo contrário, a convergência teria ocorrido quando consumidores individuais, por intermédio de sua interação social com outros consumidores, alteraram seu ponto de vista sobre uma mídia em particular. Em outras palavras, o conteúdo da internet compete diretamente com serviços de radiodifusão, por exemplo, se a percepção dos consumidores considerar tais conteúdos como um só fenômeno. Assim, Jenkins sugere que a convergência é um processo que ocorre no pensamento do consumidor individual.

Outra definição relevante sobre convergência indica que ela está no "reino das possibilidades quando ocorre uma cooperação entre imprensa e radiodifusão para a oferta de conteúdo multimídia por intermédio do uso de computadores e da internet". ${ }^{13}$ Esta definição parece colocar as mídias impressa e radiodifusora como protagonistas da era da convergência. Como será discutido mais à frente neste estudo, esta definição é manipulada pela indústria radiodifusora brasileira para ganhar controle sobre a distribuição de conteúdo na internet.

A revisão completa das definições de convergência teria requerido uma pesquisa em separado, na medida em que o conceito de convergência aceita inúmeros significados. ${ }^{14}$ A convergência é o resultado unificado de revoluções tecnológicas: tanto a do analógico para o digital, quanto a da computação em rede, assim como a percepção pública de tal transformação. Em especial, Grant e Wilkinson definiram convergência como uma "mistura de indústrias de mídia, telecomunicações e computação, e a união de todas as formas de comunicação mediadas na forma digital". ${ }^{15}$ Esta definição é semelhante à fornecida pelo Newton's Telecom Dictionary, segundo o qual a

${ }^{12}$ JENKINS, Henry. (2006). Convergence Culture: Where Old and New Media Collide. New York: New York University Press, p. 3.

${ }^{13}$ LAWSON-BORDERS, Gracie. (2005). Media Organizations and Convergence. Routhledge, p. 4.

${ }^{14}$ GRANT, August [et al.]. (2009). Understanding Media Convergence: The State of the Field. New York: Oxford University Press, p. 4.

${ }^{15}$ GRANT, August [et al.]. Op. cit., p. 5. 
convergência é a tendência à confusão entre equipamentos eletrônicos, computador e indústrias de telecomunicações, bem como a circunstância de alianças e acordos para o avanço sobre os mercados uns dos outros. ${ }^{16}$

A convergência é vista como uma ameaça por algumas indústrias e como uma oportunidade, por outras. A esse respeito, é importante distinguir duas modalidades de convergência, que têm efeitos distintos. ${ }^{17} \mathrm{~A}$ primeira modalidade é a convergência tecnológica, que consiste no uso de uma mesma rede para transporte de serviços e sinais de voz, dados ou vídeo. Neste tipo de convergência, encontram-se as possibilidades mais promissoras de economias de escopo, uma vez que os custos não recuperáveis tendem a aumentar em decorrência de investimentos em infraestrutura. A segunda modalidade é a convergência comercial, que se refere à reunião de produtos comerciais. Neste caso, o mesmo provedor de serviços está apto a oferecer a um consumidor um pacote com serviços diferentes como voz, vídeo e dados. Aqui, a produtividade e eficiência são mais limitadas que na primeira modalidade de convergência tecnológica, devido à restrição nos benefícios de fusões e aquisições no mercado. Como será visto nos próximos parágrafos, a definição de convergência adotada neste trabalho assemelha-se mais à primeira modalidade acima citada, na medida em que ela se concentra mais estritamente na regulação de telecomunicações.

Além disso, é possível partir do princípio de que a convergência se refere ao modo como as comunicações sem fio, impressas, por cabo, por satétite, por rádio e televisão tendem a se misturarem com computadores e internet e a serem assim entendidas pelo público. Em outras palavras, a convergência implica a criação de uma rede de distribuição comum para substituição de redes previamente distintas, tais como as redes de telefonia, televisão e de computação pessoal. ${ }^{18}$ A convergência transforma a distribuição de uma ampla gama de produtos e serviços. Na medida em que

\footnotetext{
${ }^{16}$ NEWTON, Harry. (2002). Newton's Telecom Dictionary. 18 ${ }^{\mathrm{a}}$ ed., New York: COM Books, p. 316.

${ }^{17}$ TUROLLA, Frederico Araujo [et al.]. (2007). Concorrência, convergencia e universalização no setor de telecomunicações no Brasil. São Paulo: Pezco Pesquisa e Consultoria, p. 26.

${ }^{18}$ YOFFIE, David B. (1997). Competing in the Age of Digital Convergence. Boston: Harvard Business School Press, p. 161. 
a convergência se apresenta como um conceito de caráter tecnológico, ela evolui e se transforma juntamente com o desenvolvimento da tecnologia.

$\mathrm{O}$ conceito de convergência será discutido em maior profundidade mais à frente. Deve-se atentar ainda para o fato de que a convergência significa a derrocada de barreiras clássicas e estáveis construídas no ponto de contato entre os serviços de telecomunicações nas últimas décadas. Por isso, para o propósito deste estudo, utiliza-se a seguinte definição de convergência: a mitigação de barreiras formais existentes na prática entre serviços de telecomunicações (cabo, satélite, radiodifusão, celulares) e a internet. Esta definição não é senão um fato que pode ser facilmente verificado. Hoje, qualquer um é capaz de fazer uma ligação de voz pela internet, baixar conteúdo da rede mundial de computadores por telefones celulares, acessar a internet por TV a cabo, e assim por diante.

Em suma, aplicativos de protocolo de internet (IP) têm o potencial de substituir várias indústrias hoje existentes e o conceito de convergência é utilizado para pesquisa de resultados diversos deste processo. As operadoras dominantes e os atuais líderes industriais geralmente procuram um conceito de convergência que lhes possibilite continuar a exercer seu poder sobre novas indústrias. Por outro lado, as indústrias emergentes frequentemente tentam mostrar que os seus serviços são de natureza diferente dos ofertados por indústrias tradicionais. Esta disputa e o modo como compreendemos a natureza da convergência determinará como regularemos serviços no futuro.

Dada esta definição de convergência, é importante reconhecer a sua íntima relação com a internet. $\mathrm{O}$ termo internet tem sido concebido como reunidor do conjunto de desenvolvimentos tecnológicos oriundos da convergência. Ao mesmo tempo em que a internet se desenvolvia, outras transformações ocorriam no mundo das indústrias e tecnologias de mídia. Tais mudanças afetaram profundamente o que mais tarde viria a se tornar a rede mundial de computadores [World Wide Web]. Os vários aspectos de dita influência foram descritos por Lucy Küng no seu livro The Internet and the Mass Media ${ }^{19}$, em que defendeu a internet como um termo abrangente da diversidade de desenvolvimento tecnológico. A visão da autora foi partilhada por Steven Sheperd, que viu na internet um meio de grande

${ }^{19} \mathrm{KÜNG}$, Lucy [et al.]. (2008). The Internet and the Mass Media. Thousand Oaks, California: Sage Publications. 
influência, bem como o melhor resultado da convergência tecnológica. ${ }^{20}$ Além disso, a convergência pode ser vista como resultante do casamento entre o engenhoso formato da televisão e o caráter ilimitado de provimento de informação da internet. ${ }^{21}$

A partir da relação que foi estabelecida entre internet e convergência, a próxima seção discutirá as diversas facetas da convergência.

As várias facetas da convergência

À semelhança do que ocorre com a árdua tarefa de definição da convergência, é importante ter em mente que, para propósitos regulatórios, o desenvolvimento de uma nova tecnologia deve ser entendida em um contexto que leve em conta a velocidade, os meios e as consequências em que dita evolução é apresentada. Em outras palavras, compreender a convergência é importante, mas compreender como ela afeta e chega ao público em geral é ainda mais importante para os reguladores. Por exemplo, o modo como um novo produto convergente é introduzido no mercado, os impactos suportados por produtos e indústrias existentes e o modo como isto afeta os serviços também são premissas relevantes para uma regulação precisa e adequada. A tecnologia, por si só, não é capaz de transformar a sociedade. Na mesma linha, a sociedade, por si só, é incapaz de controlar todas as variáveis do desenvolvimento tecnológico, ao menos de modo sistemático e organizado. Os impactos que a convergência terá na indústria de telecomunicações, no conteúdo eletrônico e nos seus resultados são imprevisíveis. $^{22}$

Sob a luz da definição de convergência acima adotada, o fenômeno da convergência tecnológica pode ser abordado sob vários ângulos. Deve-se fazer uma distinção entre dois grupos: a convergência de produtos

${ }^{20}$ SHEPERD, Steven. (2002). Telecommunications Convergence: How to Bridge the Gap Between Technologies and Services. New York: McGraw-Hill Companies, p. 11.

${ }^{21}$ SEIB, P. (2001). Going Live. Lanham, MD: Rowman \& Littlefield, p. 7.

${ }^{22}$ CASTELLS, Manuel. (2003). A sociedade em rede. A era da informação: economia, sociedade e cultura. São Paulo: Paz e Terra, p. 43.

Revista de Direito, Estado e Telecomunicações, v. 3, n. 1, p. 111-166 (2011)

DOI: https://doi.org/10.26512/lstr.v3i1.21669 
substitutos e a convergência de produtos complementares. ${ }^{23} \mathrm{O}$ primeiro grupo pode ser visto quando o consumidor escolhe um produto entre duas opções, em que ambas têm características comuns, permitindo, assim, fácil mudança de escolha. $\mathrm{O}$ segundo tipo de convergência ocorre quando ambos os produtos funcionam melhor em conjunto do que quando utilizados em separado. Neste último caso, as empresas podem, por exemplo, padronizar a produção de equipamentos para extrair daí externalidades positivas. ${ }^{24} \mathrm{Em}$ ambos os grupos de convergência, os produtos não são correlatos entre si no início e podem ser substituídos ou complementados um pelo outro em uma fase posterior.

A noção de convergência, portanto, abarca uma ampla gama de temas. Grant e Wilkinson delineiam as seguintes dimensões da convergência: ${ }^{25}$ a) de analógico para digital, representado pela transição de virtualmente qualquer mídia de analógico para virtual; b) as redes de computadores, que são capazes de armazenar, compartilhar, manejar e editar qualquer sinal digital em um computador; c) a multiplicidade de conteúdos de mídia, que permitem que se tome um conteúdo de meios de comunicação tradicionais e o disponibilize na internet; d) a dimensão de propriedade, que corresponde à condição de propriedade de dois ou mais veículos de comunicação servindo ao mesmo mercado por uma entrada única; e) a colaboração, que significa que várias editoras, organizadores e diretores de noticiários têm abraçado a oportunidade de colaboração com meios de comunicação antes vistos como competidores; f) a coordenação, que ocorre quando dois meios de comunicação que não partilham de um controlador comum adotam práticas convergentes idênticas ou similares.

Para o propósito deste artigo, somente as três primeiras dimensões de convergência acima mencionadas serão utilizadas. As outras dimensões de convergência são relevantes e muito influentes na forma como os atores de

${ }^{23}$ GREENSTEIN, Shane; KHANNA, Tarun. (1997). What Does Industry Convergence Means? In: YOFFIE, David B. (ed.). Competing in the Age of Digital Convergence. Boston: Harvard Business School Press, p. 203.

${ }^{24}$ Neste particular, Greenstein e Khanna utilizam o termo pacote padrão [standard bundle], querendo com isso significar que uma cesta de produtos é organizada de tal modo que cada parte é projetada como parte de um sistema maior.

${ }^{25}$ GRANT, August [et al.]. (2009). Understanding Media Convergence: The State of the Field. New York: Oxford University Press, p. 5-11. 
mídia se comportam e influenciam a regulação quando enfrentam desafios tecnológicos que demandam sua atenção. Um bom exemplo disso se dá no caso de mudanças culturais vivenciadas por uma empresa em um ambiente convergente. Existem pessoas de culturas diferentes trabalhando na imprensa, na radiodifusão e em outras mídias eletrônicas. Os meios de comunicação e métodos utilizados são distintos. As radiodifusoras, por exemplo, "reconhecem a natureza visual da sociedade e sua habilidade de capturar a atenção do espectador". ${ }^{26}$ Tais características dissonantes exercem uma função relevante no modo como a mídia tradicional reage aos efeitos da convergência na distribuição eletrônica.

De modo geral, os variados formatos e traços específicos da convergência desempenham um papel central na forma como o conceito de convergência é percebido. Assim, todas as idiossincrasias devem ser levadas em conta cuidadosamente e sopesadas quando da adoção e elaboração de um novo modelo regulatório.

\section{Definição de serviços de telecomunicações e o problema da convergência}

Esta seção analisa os serviços de telecomunicações atuais em meio a definições presentes nos ordenamentos jurídicos brasileiro e norteamericano, bem como mostra como os rápidos avanços tecnológicos nesta indústria criaram a circunstância em que certas definições regulatórias perderam parcialmente sua significância. Como explica Küng, a convergência ameaça as distinções tradicionais entre formas de regulação estanques na mídia tradicional. Além disso, a convergência faz desaparecerem as diferenças entre as formas de regulação da radiodifusão e das telecomunicações. ${ }^{27}$

\footnotetext{
${ }^{26}$ LAWSON-BORDERS, Gracie. (2005). Media Organizations and Convergence. Routhledge, p. 16.

${ }^{27} \mathrm{KÜNG}$, Lucy [et al.]. (2008). The Internet and the Mass Media. Thousand Oaks, California: Sage Publications, p. 107.

Revista de Direito, Estado e Telecomunicações, v. 3, n. 1, p. 111-166 (2011)

DOI: https://doi.org/10.26512/lstr.v3i1.21669
} 
Definições dos principais serviços de telecomunicações

Nos Estados Unidos, a história da regulação de telecomunicações iniciou-se no alvorecer do século XX. Mesmo antes, no século XIX, existiam regras federais sobre o telégrafo, mas tanto a telegrafia quanto a telefonia somente foram submetidas a arcabouços formais regulatórios no início da década de 1910, por intermédio do Mann-Elkins Act. O passo fundamental, todavia, de imposição da regulação na indústria consistiu no Communications Act de 1934, que instituiu a Comissão Federal de Comunicações [Federal Communications Commission (FCC)] como a agência reguladora de comunicações dos Estados Unidos. O Communications Act de 1934 firmou as fundações para uma regulação federal sistemática. ${ }^{28} \mathrm{O}$ Act de 1934 foi alterado em vários momentos dando origem ao Cable Communications Policy Act de 1984, ao Cable Television Consumer and Protection Act de 1992 e, finalmente, ao Telecommunications Act de 1996. Algumas das definições utilizadas neste artigo são contempladas no Act de 1996.

Transformações semelhantes ocorreram no Brasil. A primeira iniciativa compreensiva de codificação da regulação de comunicações foi realizada em 1962, quando o Código Brasileiro de Telecomunicações (CBT) foi aprovado. O CBT foi parcialmente revogado pela Lei Geral de Telecomunicações de 1997. A regulação de radiodifusão permaneceu, em grande parte, regida pelo Código Brasileiro de Telecomunicações.

O objetivo de se definir um serviço de telecomunicações está no esclarecimento dos serviços que uma operadora de telecomunicações pode ou não oferecer. Tal definição é importante para prevenir situações em que uma operadora de telecomunicações passe a oferecer serviços que não the foram outorgados. Em um ambiente convergente, entretanto, esta separação entre serviços outorgados e não-outorgados consiste em uma barreira imposta às operadoras de telecomunicações de prestarem novos serviços sobre a mesma plataforma e a mesma faixa de radiofrequência.

Em virtude da convergência, no entanto, tal distinção quanto aos serviços que cada operadora de telecomunicações pode ofertar tem sido

${ }^{28}$ WALDEN, Ian (ed.). (2009). Telecommunications Law and Regulation. 3ed., Oxford: Oxford University Press, p. 212. 
obscurecida. As seções seguintes apresentam as definições hoje praticadas para os serviços de telecomunicações e propõem identificar as principais características desses serviços gravadas no arcabouço regulatório de telecomunicações.

\section{Radiodifusão}

De acordo com o art. $6^{\circ}$, do Código Brasileiro de Telecomunicações, o serviço de radiodifusão é o "destinado a ser recebido direta e livremente pelo público em geral, compreendendo radiodifusão sonora e televisão". ${ }^{29}$ Esta definição é demasiado ampla e ineficaz na delimitação das fronteiras dos serviços de radiodifusão. A dicção do dispositivo deixa claro que a radiodifusão inclui o rádio e a televisão, mas não limita o provedor do serviço a estes dois tipos de serviço. Isso significa que qualquer outro serviço, seja direta ou indiretamente acessado pelo público em geral, pode ser percebido como radiodifusão. Exemplificativamente, se a Nextel [até então autorizada do Serviço Móvel Especializado ou trunking], no Brasil, envia um sinal de forma direta e irrestrita ao público em geral, este sinal pode ser considerado radiodifusão? Tal mensagem pode ser classificada como serviço de radiodifusão? O que diferencia a radiodifusão de outros serviços de telecomunicações? Para responder a estas questões, é importante deixar de lado a definição do serviço, que é demasiado ampla e incapaz de delimitar fronteiras precisas. É vital que se concentre a atenção sobre as características intrínsecas da radiodifusão para se determinar, com isso, os fatores que a diferenciam de outros serviços de telecomunicações.

Esta pesquisa revela várias diferenças entre os serviços de telecomunicações no Brasil. Em particular, a radiodifusão é caracterizada pelo seguinte: a) seu conteúdo é definido pela radiodifusora; b) a

${ }^{29}$ Esta definição se encontra na parte não revogada do Código Brasileiro de Telecomunicações. As radiodifusoras trabalharam fortemente no Congresso brasileiro para que esta definição permanecesse intocada. Com isso, a Lei Geral de Telecomunicações não contempla a regulação de serviços de radiodifusão, senão no tocante a gestão técnica do espectro pertinente. Ela somente lida com serviços de telecomunicações. A partir desta distinção, fica claro que, ao contrário do que ocorre nos Estados Unidos, na indústria de comunicações do Brasil, há uma clara separação entre serviço de telecomunicação e serviço de radiodifusão. A radiodifusão não é somente um tipo de telecomunicações; ela é tratada como uma categoria inteiramente distinta de serviços. Esta questão será aprofundada mais a frente.

Revista de Direito, Estado e Telecomunicações, v. 3, n. 1, p. 111-166 (2011)

DOI: https://doi.org/10.26512/1str.v3i1.21669 
radiodifusora é responsável pelos conteúdos transmitidos; c) o conteúdo é transmitido pelo espectro para dois ou mais dispositivos simultaneamente segundo janelas de programação predeterminadas pela radiodifusora; d) a radiodifusora é obrigada a transmitir um número de programas gratuitamente, tais como propaganda eleitoral, Hora do Brasil, dentre outros, na televisão ou no rádio, ou informações dos poderes da República no rádio; e) transmissão unidirecional sem interatividade com o canal de retorno, embora esta característica tradicional tenha sido relativizada pela introdução da TV digital terrestre, que permite interatividade e, com isso, torna-se bidirecional; f) há um número mínimo de horas que uma radiodifusora deve transmitir diariamente (art. 38,e, do CBT); g) há um limite máximo de tempo de transmissão de propaganda comercial por canal de programação; h) trata-se de um serviço terrestre; i) trata-se de um serviço de tipo pontoárea, em que todos que se encontrem dentro da área de recepção estão habilitados a receber o sinal; j) a radiodifusora não sabe quem está recebendo o sinal de programação, embora o número de pessoas que recebe o sinal seja conhecido. Esta característica também pode vir a ser atenuada com a interatividade da TV digital; k) o usuário do serviço não necessita de autorização para sê-lo e não precisa pagar para receber o sinal; 1) não há contratos formais entre a radiodifusora e os usuários do serviço; m) os dispositivos de recepção do sinal são baratos e de fácil acesso; n) o consumidor pode escolher o local em que receberá o sinal (isto significa que o consumidor é livre para levar a televisão para sua casa, escritório ou qualquer outro lugar); o) a propaganda comercial transmitida durante a programação é feita a título oneroso e suportada pelo anunciante.

Dessa forma, o modelo brasileiro de regulação da radiodifusão é deveras semelhante ao dos Estados Unidos. Muitas características das radiodifusoras brasileiras são compartilhadas pelas radiodifusoras norte-americanas. Esta coincidência não é de surpreender, haja vista que o modelo de negócios brasileiro para o rádio e televisão foi grandemente inspirado no sucesso norte-americano. ${ }^{30}$

${ }^{30}$ JUSTEN FILHO, Marçal. (2002). O direito das agências reguladoras independentes. São Paulo: Dialética, p. 137.

Revista de Direito, Estado e Telecomunicações, v. 3, n. 1, p. 111-166 (2011) 


\section{TV a cabo}

O segundo tipo de serviços de telecomunicações analisado é a TV a cabo. A história do desenvolvimento da TV a cabo é inteiramente distinta no Brasil e nos Estados Unidos. Nos Estados Unidos, os primeiros passos da indústria de TV a cabo foram dados na década de 1950 com a introdução das antenas comunitárias, que foram pensadas pela FCC como uma solução para suprir a deficiência de serviços de radiodifusão em comunidades rurais. Pequenas cidades em conjunto eram capazes de gerar ganhos comerciais suficientes para atraírem o interesse das redes de televisão em lhes fornecerem programação. ${ }^{31} \mathrm{~A}$ era da $\mathrm{TV}$ por Antenas Comunitárias [Community Antennas TV (CATV)] deu origem à TV a Cabo [Cable TV] quando os provedores de serviços puderam atrair mais assinantes ao oferecerem canais que não estavam disponíveis na radiodifusão. Ao final, os sistemas de televisão por antenas comunitárias passaram a oferecer conteúdo televisivo aos assinantes, competindo no terreno antes reservado às radiodifusoras.

No Brasil, pelo contrário, a TV a cabo surgiu somente em meados da década de 1990 após uma dura batalha contra as radiodifusoras, que viam os prestadores de TV a cabo como competidores diretos. A Lei do Cabo (Lei 8.977/95) foi finalmente aprovada em 1995. O mercado para TV a cabo, no Brasil, encontrava-se delimitado por barreiras de entrada e pesada regulação. Como foi dito na parte inicial deste artigo, o número de assinantes é consideravelmente menor do que nos Estados Unidos.

A Lei do Cabo brasileira, em seu art. $2^{\circ}$, define o serviço de TV a Cabo como o "serviço de telecomunicações que consiste na distribuição de sinais de vídeo e/ou áudio, a assinantes, mediante transporte por meios físicos". No parágrafo único do art. $2^{\circ}$, a Lei do Cabo acrescenta que "a interação necessária à escolha de programação e outras aplicações pertinentes ao serviço" estão incluídas no serviço. Levando em conta esta definição, é possível assumir que o serviço de TV a Cabo consiste em virtualmente qualquer serviço de telecomunicações desde que transporte seu sinal por meios físicos, embora a interpretação oficial adotada pelo órgão regulador brasileiro seja bem mais restritiva. Assim, embora seja uma questão

${ }^{31}$ TEETER, Dwight L. [et al.]. (2008). Law of Mass Communications: Freedom and Control of Print and Broadcast Media. New York: Foundation Press, p. 742.

Revista de Direito, Estado e Telecomunicações, v. 3, n. 1, p. 111-166 (2011)

DOI: https://doi.org/10.26512/lstr.v3i1.21669 
controversa, é possível defender-se que qualquer conteúdo de áudio ou vídeo transmitido por meios físicos pela internet pudesse ser considerado serviço de TV a Cabo, desde que outras condições fossem cumpridas, tais como a assinatura, a disponibilidade de programação por período de tempo, dentre outras.

Em comparação com os serviços de radiodifusão, a TV a cabo possui uma miríade de características que fazem dela um serviço diferenciado. Algumas destas características são: a) a TV a cabo é um serviço pontomultiponto; b) o equipamento necessário à recepção do sinal (set top box) não está usualmente disponível para venda ao grande público; c) o serviço deve ser prestado no endereço contratado pelo assinante; d) os prestadores de serviço de TV a cabo são pagos diretamente pelos consumidores do serviço; e) não há limitação à duração ou ao número de propagandas comerciais; f) trata-se de serviço predominantemente unidirecional; g) o prestador do serviço é responsável pelo conteúdo transmitido, com a exceção dos canais de distribuição obrigatória [must-carry channels] $;{ }^{32} \mathrm{~h}$ ) o serviço é fornecido aos assinantes por meios físicos; i) é exigido um contrato escrito entre o prestador do serviço e o assinante; $j$ ) os prestadores do serviço de TV a cabo devem disponibilizar aos consumidores, antecipadamente, suas grades de programação; k) mesmo no caso de programas pay-per-view, o consumidor deve esperar até o momento predeterminado em que o programa torna-se acessível; 1) a programação é transmitida como um todo para cada consumidor; m) a prestadora de serviço de TV a cabo sabe exatamente se, onde e que programas o consumidor está acessando; n) a prestadora de serviço de TV a cabo pode, remotamente, habilitar ou desabilitar o set top box do consumidor.

Como se pode ver, a TV a cabo tem características distintas da radiodifusão. Tais distinções são decisivas para que os dois serviços sejam diferenciados na era da convergência tecnológica. Ao mesmo tempo, as diferentes funções entre radiodifusão e TV a cabo são suficientes para revelar que, embora a convergência tecnológica caminhe para apagar as

${ }^{32} \mathrm{À} \mathrm{semelhança} \mathrm{do} \mathrm{que} \mathrm{ocorre} \mathrm{nos} \mathrm{Estados} \mathrm{Unidos,} \mathrm{a} \mathrm{regulação} \mathrm{brasileira} \mathrm{de} \mathrm{TV} \mathrm{a}$ Cabo também prevê canais de distribuição obrigatória. No Brasil, estes canais incluem, entre outros, os canais de radiodifusão, os canais do Senado Federal e da Câmara de Deputados, o canal da TV Justiça e o canal do Poder Executivo. 
fronteiras entre os serviços de telecomunicações, ela não tem o condão de reuni-los em um fenômeno único. Existem qualidades peculiares que permanecem presentes em um reino específico de serviços, que não são compartilhadas pelos demais.

\section{Internet}

Finalmente, é necessário examinar o ambiente regulatório aplicável ao conteúdo distribuído pela internet, analisar as suas características e evidenciar seus pontos de contato com a radiodifusão e a TV a cabo. A legislação brasileira define vagamente os serviços de internet. A Norma $\mathrm{n}$. 004/95, sobre uso dos meios da rede pública de telecomunicações para acesso à internet, aprovada pela Portaria n. 148, de 31 de maio de 1995, do Ministério das Comunicações define internet como "o conjunto de redes, os meios de transmissão e comutação, roteadores, equipamentos e protocolos necessários à comunicação entre computadores, bem como o software e os dados contidos nestes computadores". Além disso, a internet é considerada um serviço de valor adicionado definido como a "atividade que acrescenta, a um serviço de telecomunicações que lhe dá suporte e com o qual não se confunde, novas utilidades relacionadas ao acesso, armazenamento, apresentação, movimentação ou recuperação de informações" (art. 61, da Lei 9.472/97, Lei Geral de Telecomunicações). O provedor de serviço de conexão à internet pode ser um mero consumidor de serviços de telecomunicações ou mesmo o prestador de serviço de telecomunicações exercendo simultaneamente as duas atividades. Além disso, o acesso à internet deve ser ofertado sobre uma plataforma de um serviço de telecomunicações existente, embora não se configure, ele mesmo, como um serviço de telecomunicações.

Esse serviço de valor adicionado se assemelha ao serviço de informação [information service], conforme definido pela FCC. ${ }^{33}$

\footnotetext{
${ }^{33}$ As implicações do conceito de serviço de informação podem ser vistas no caso National Cable \& Telecommunications Association et al. v. Brand X Internet Services et al., 545 U.S. 967 (2005). Em síntese, a Suprema Corte dos Estados Unidos decidiu que a definição de serviço de informação dada pela FCC era válida. A FCC considerou os serviços de informação como serviços distintos dos serviços de telecomunicações.
}

Revista de Direito, Estado e Telecomunicações, v. 3, n. 1, p. 111-166 (2011)

DOI: https://doi.org/10.26512/lstr.v3i1.21669 
O problema com essa moldura regulatória está no fato de que a revolução convergente tornou possível aos provedores de serviço de conexão à internet oferecerem programas de vídeo e áudio equiparáveis aos ofertados na radiodifusão e TV a cabo. Assim, a equivalência direta entre tais serviços traria consequências dramáticas para a regulação da indústria, como discutido mais a frente.

Uma clara distinção entre a internet e outras mídias foi firmada no caso Janet Reno v. American Civil Liberties Union $(A C L U)^{34}$, segundo a qual a internet teria as seguintes características:

a) a primeira característica se refere às instalações de que uma pessoa deve dispor para acessar a internet. Isto se aplica tanto ao consumidor que utiliza a internet sem fins lucrativos, quanto ao consumidor comercial. O número de barreiras e restrições que podem ser opostas como limites tecnológicos ou físicos à exploração do ciberespaço por qualquer pessoa que desejar nele ingressar é limitado. ${ }^{35}$

b) Em segundo lugar, inexistem barreiras significativas para que provedores de serviço de conexão à internet enviem informações e para que usuários as recebam pela internet. $\mathrm{O}$ grau de dificuldade que uma pessoa encontra para enviar conteúdo pela internet é o mesmo experimentado por quem recebe os dados.

c) Em terceiro lugar, devido à simplicidade experimentada pelas pessoas de envio, pesquisa e recebimento de informação pela internet, há uma diversidade incomparável e uma quantidade indeterminável de conteúdo presente e disponível na internet para seus usuários. Nas indústrias de radiodifusão e TV a cabo, o conteúdo disponível é sempre determinado e limitado pelo prestador do serviço.

d) Finalmente, a internet permite ampla liberdade no acesso a qualquer conteúdo. Tal liberdade gera uma notável igualdade entre os que

\footnotetext{
${ }^{34}$ Reno v. American Civil Liberties Union, 521 U.S. 844 (1997).

${ }^{35}$ FARRELL, Joseph; WEISER, Philip. (2003). Modularity, Vertical Integration and Open Access Policies: Towards a Convergence of Antitrust and Regulation in the Internet Age. In: Harvard Journal of Law \& Technology 17(1): 86-134, p. 91.
} 
utilizam a rede mundial de computadores. A internet não discrimina entre um usuário A ou B, tratando-os como iguais. ${ }^{36}$

As características acima transformam a internet em uma entidade desconhecida para a tradicional regulação de serviços de telecomunicações. As características de outros serviços, a clara precisão das suas fronteiras e as premissas que têm guiado a regulação de serviços de telecomunicações com base em seu conteúdo por mais de um século estão chegando ao fim. A dinâmica de um novo cenário altera as presunções sedimentadas no setor e torna obsoleta a regulação atual.

A rigidez das definições de serviços de telecomunicações e seus efeitos sobre a convergência

A convergência é claramente uma revolução ${ }^{37}$ e veio para ficar. ${ }^{38}$ Além disso, a convergência se configura na sexta revolução informacional. ${ }^{39}$ As outras revoluções, conforme exposto por Irving Fang, foram: a) o contato entre o alfabeto fonético fenício e os papiros egípcios no século VIII a.C., na Grécia; b) a invenção da imprensa, na segunda metade do século XV; c) a revolução da mídia de massa, que surgiu da conjunção entre a produção industrial do papel e a invenção do telégrafo, abrindo caminho para a transmissão da informação de forma rápida e em grandes distâncias; d) a revolução do entretenimento do final do século XIX, como consequência da emergência de novas tecnologias como as câmeras e técnicas de gravação do som; e) o chamado Communication Toolshed Home do período pós $2^{\mathrm{a}}$ Guerra Mundial, que transformou a habitação média norte-americana em um centro de entretenimento. A quinta revolução foi acompanhada do acesso à informação, inclusive por dispositivos como o telefone, a televisão, o rádio,

${ }^{36} \mathrm{~A}$ persistência desta última característica está em risco devido a atitudes recentes dos controladores das redes, que têm controlado o fluxo de bits na internet. A reação a esta interferência é conhecida como neutralidade de rede e será abordada adiante.

${ }^{37}$ Por revolução, se entende o remodelamento dos fundamentos dos modelos regulatórios de telecomunicações previamente existentes.

${ }^{38}$ LAWSON-BORDERS, Gracie. (2005). Media Organizations and Convergence. Routhledge, p. 184.

${ }^{39}$ FANG, Irving. (1997). History of Mass Communication: Six Information Revolutions. Boston: Focal Press, p. 15. 
técnicas mais avançadas de impressão, transporte barato e serviços postais. ${ }^{40}$ Finalmente, a sexta revolução é chamada por Fang de autoestrada da informação [information highway] e ainda está se concretizando por intermédio da convergência tecnológica.

Dessa forma, as definições atuais de serviços de telecomunicações não são mais adequadas à delimitação do que pode ser licitamente implementado por um serviço. Essa conclusão não decorre somente de uma restrição teórica. Os efeitos dessa diminuição da capacidade de se definir propriamente um serviço e do que um prestador está autorizado a fazer causa um distúrbio profundo no já tênue equilíbrio regulatório que une a indústria de telecomunicações. Atualmente, não é mais possível identificar e separar os distintos serviços de telecomunicações, na medida em que se verifica um alto grau de insegurança legal e regulatória para investidores e atores de mercado. Um setor industrial sem claras regras gera desincentivos para novos investimentos.

Embora a convergência tenha derrubado o muro que separava os serviços de telecomunicações, ainda persistem várias características peculiares a cada serviço e, quando detidamente identificadas, permitem precisar o que tais serviços podem ou não oferecer. Steven Shepard explica que a convergência não significa necessariamente o caos e a barbárie tecnológica ou mesmo uma Idade das Trevas no mercado de conteúdo eletrônico. ${ }^{41}$ Não obstante esta possibilidade, a regulação não é tão dinâmica quanto ela poderia ser para manter o passo do incessante desenvolvimento de novas tecnologias. Essa conclusão é válida para o Brasil e para os Estados Unidos e, cada vez mais, se apresenta como uma qualidade intrínseca à indústria de telecomunicações.

Tais considerações, quanto vistas em conjunto, levam a uma outra inferência. Se o cenário em transformação da indústria de telecomunicações com enfoque em conteúdo não for adequadamente enfrentado e com cuidado, ele irá inevitavelmente atrasar a fruição dos benefícios da convergência. Para que a convergência dê resultados e cumpra seu

${ }^{40}$ FANG, Irving. Op. cit., p. 138.

${ }^{41}$ SHEPARD, Steven. (2002). Telecommunications Convergence: How to Bridge the Gap Between Technologies and Services. $2^{\mathrm{a}}$ ed., New York: McGraw-Hill Companies, p. 339. 
potencial, as antiquadas estruturas regulatórias de mídia eletrônica e plataformas de conteúdo têm que adequar gradualmente suas relações com os serviços de telecomunicações de distribuição de informação. A recusa em se reconhecer esse fenômeno e em se admitir que a rígida estrutura regulatória da indústria deve ceder espaço a um conjunto de regras mais dinâmico e flexível atrasa o processo convergente com consequências nefastas para o grande público e para o livre trânsito de informações em geral.

Por suposto, existe um jogo de poderes a ser considerado na equação por um novo modelo regulatório. As agências reguladoras são atores dominantes que se esforçam para manter o status quo. Apesar dos obstáculos, devem ser vislumbradas regras e princípios que possam se apresentar como pilares de um novo sistema.

\section{Breves considerações para um novo arcabouço regulatório}

Embora não seja o propósito deste artigo desenvolver um corpo de princípios e regras que estabeleçam os fundamentos de um futuro modelo regulatório que esteja embasado na dinâmica da convergência, o esboço delineado abaixo será útil para situar as questões discutidas nas etapas seguintes do estudo.

Tendo isso em vista, é importante que se identifiquem as regras básicas que vinculam os reguladores quando estabelecem as linhas mestras para a indústria nascente. Exemplificativamente, os reguladores devem: a) criar incentivos aos fabricantes para se concentrarem em serviços, soluções e ferramentas que permitam competição entre prestadores de serviços; b) criar incentivos aos fabricantes para desenvolvimento de sistemas e serviços compatíveis; ${ }^{42}$ c) estimular os prestadores de serviços a expandirem suas competências, adicionando funcionalidades de Provedores de Aplicativos [Application Service Providers (ASPs)], o que possibilita aos prestadores ofertarem mais do que somente o sinal telefônico; ${ }^{43}$ d) criar uma licença

\footnotetext{
${ }^{42}$ LAWSON-BORDERS, Gracie. (2005). Media Organizations and Convergence. Routhledge, p. 185.

${ }^{43}$ SHEPARD, Steven. (2002). Telecommunications Convergence: How to Bridge the Gap Between Technologies and Services. $2^{\mathrm{a}}$ ed., New York: McGraw-Hill Companies, p. 340.
}

Revista de Direito, Estado e Telecomunicações, v. 3, n. 1, p. 111-166 (2011)

DOI: https://doi.org/10.26512/lstr.v3i1.21669 
única que englobe muitos dos serviços de telecomunicações e de informação da atualidade, fazendo, com isso, que os custos de burocracia sejam diminuídos e que o controle sobre os serviços por parte da agência reguladora sejam simplificados. ${ }^{44}$ Dita estratégia também criaria um sistema de autorização semelhante para serviços equiparáveis, independentemente da tecnologia empregada pelos prestadores de serviço.

Estes singelos princípios regulatórios, se adotados, permitiriam firmar uma base sólida para um novo quadro regulatório. A convergência é um fenômeno que requer esforços regulatórios para tornar-se mais uniforme e robusta. Trata-se de um ciclo virtuoso reforçado pela associação de novos membros. Em termos técnicos, a convergência se apresenta como externalidades de rede ou efeitos de rede [network effects]. À medida que a rede se expande, os benefícios se acumulam. ${ }^{45}$ Todos os participantes da rede ganham mais valor com o crescimento da rede. O efeito de rede é, de fato, real para dispositivos convergentes, na medida em que, quanto maior for a convergência, mais benefícios serão usufruídos pelos usuários da rede em termos de possibilidades mais abrangentes oferecidas por um número crescente de participantes.

Ao contrário do que ocorre com os efeitos de rede do sistema telefônico, a convergência não tende a um modelo de monopólio natural, pois ela se afigura como mais do que simples manifestações de externalidades positivas de uma rede de telefonia comum. O fenômeno da convergência não é limitado por barreiras de redes de última milha, como também não oferece somente serviços de voz. De fato, a convergência é exatamente o oposto disso. A percepção mais arrojada de convergência implica a possibilidade de prestação de qualquer serviço sobre qualquer plataforma tecnológica existente.

Como um todo, qualquer regulação de sucesso terá que levar em consideração o fato de que o fenômeno da convergência tem efeitos de rede

\footnotetext{
${ }^{44}$ Diretiva 2002/20/EC, do Parlamento Europeu e do Conselho da União Europeia, de 7 de março de 2002, sobre a autorização de redes e serviços de comunicação eletrônica. Vide: http://ec.europa.eu/information_society/topics/telecoms/regulatory/ new rf/documents/1_10820020424en00210032.pdf.

${ }^{45}$ KATZ, Michael; SHAPIRO, Carl. (1985). Network Externalities, Competition and Compatibility. In: Am. Econ. Rev. 75(424).
} 
similares ao da rede telefônica, mas ele não é e não deve ser entendido como um monopólio natural.

\section{A batalha pelo controle do conteúdo eletrônico no Brasil: radiodifusoras versus provedores de conteúdo pela internet}

\section{Uma breve história da indústria da radiodifusão no Brasil}

O propósito desta seção é o de analisar a disputa entre as radiodifusoras brasileiras e submeter à crítica os novos mecanismos de distribuição de conteúdo pela internet na TV a cabo. Em acréscimo, avaliar-se-á como este debate está redesenhando os modelos de distribuição de conteúdo e informação no Brasil. A melhor forma de se ter uma visão clara sobre o contexto da disputa regulatória está na análise da história dos atores envolvidos. Assim, nesta seção, serão abordados os eventos mais relevantes para a indústria de radiodifusão no Brasil, suas regras e o seu estado atual.

A radiodifusão ${ }^{46}$, que consiste no rádio e na televisão, nasceu, no Brasil, no início da década de 1920. Como ocorreu em muitos outros lugares, ela surgiu com propósitos educacionais em um momento em que o modelo de negócios do serviço não era claro. ${ }^{47}$ Todavia, devido a razões de ordem política e econômica, o modelo comercial das empresas privadas baseado

${ }^{46} \mathrm{O}$ termo radiodifusão é utilizado, no Brasil, como sinônimo de broadcasting, significando a distribuição simultânea de um sinal para o público em geral. Os dois termos, entretanto, não possuem sentidos idênticos. A radiodifusão, no Brasil, é utilizada para se referir aos serviços de rádio e televisão, enquanto, nos Estados Unidos, o termo broadcast pode ter um significado mais amplo para incluir, por exemplo, a informação enviada simultaneamente para dois ou mais dispositivos receptores por meio de uma rede de comunicações ou de dados, correio de voz, sistema de correio eletrônico, estação local de TV ou rádio, ou mesmo sistema por satélite. Vide: NEWTON, Harry. (2002). Newton's Telecom Dictionary. $18^{a}$ ed., New York: COM Books, p. 210.

${ }^{47}$ Há dois modelos maiores a serem debatidos: a) o modelo de empresas detentoras de infraestrutura essencial de transporte [common carriers] de telecomunicações, como o modelo da AT\&T, em que o canal de transmissão aberta de sinais [broadcasting channel] operava a função única de transmissão e transporte de sinais de terceiros; e b) o modelo escolhido pelos fabricantes, que defendiam a transmissão de sinais gratuita mantida por receitas de publicidade comercial.

Revista de Direito, Estado e Telecomunicações, v. 3, n. 1, p. 111-166 (2011)

DOI: https://doi.org/10.26512/lstr.v3i1.21669 
em receitas de publicidade prevaleceu. O modelo comercial triunfou, no Brasil, e é o modelo adotado até hoje na radiodifusão brasileira.

A indústria televisiva surgiu no contexto do modelo de sucesso do rádio, da propriedade privada e de receitas de publicidade comercial. No entanto, apesar de refletir um modelo de negócio inequívoco, por quase quarenta anos, a indústria radiodifusora, no Brasil, tem funcionado sem uma regulação ou arcabouço normativo preciso. $\mathrm{O}$ cenário desregulado era perfeitamente apropriado até o surgimento de competidores estrangeiros potenciais no final da década de 1950. Somente em 1962 foi aprovado pelo Congresso o Código Brasileiro de Telecomunicações (CBT). Este código firmou as regras básicas a serem seguidas pela indústria de radiodifusão por décadas que se seguiram.

Hoje, o serviço de radiodifusão ainda é considerado uma parte ou subespécie do gênero maior de serviço de telecomunicações. Em 1988, a Constituição brasileira classificou o serviço de radiodifusão como algo distinto dos serviços regulares de telecomunicações. Esta distinção tornou-se o cerne da disputa sobre o controle do conteúdo eletrônico no Brasil.

Não seria um exagero afirmar que o Código Brasileiro de Telecomunicações de 1962 era, em grande medida, o resultado do poderoso lobby das radiodifusoras brasileiras. De fato, ele foi aprovado pelo Congresso contra nada menos que 52 vetos do presidente João Goulart. A Associação Brasileira de Emissoras de Rádio e Televisão (ABERT) ${ }^{48}$ foi fundada exatamente na mesma época e ela enfrentou forte oposição presidencial.

$\mathrm{O}$ art. $6^{\circ}, d$, do Código Brasileiro de Telecomunicações definiu a radiodifusão como aquela destinada a ser recebida direta e livremente pelo público em geral, compreendendo radiodifusão sonora e televisão. Tais serviços seriam prestados diretamente pela União, ou por meio de concessões, permissões ou autorizações a empresas privadas, de acordo com o art. 32, do CBT, de 1962. Em acréscimo, o Código definiu vários critérios para prestação dos serviços de radiodifusão, tais como a limitação diária de conteúdo publicitário, prazos e condições para a concessão, entre outros.

${ }^{48} \mathrm{~A}$ ABERT é o equivalente, no Brasil, à National Association of Broadcasters $(N A B)$, dos Estados Unidos. 
Desde então, não houve nenhuma alteração substancial no marco regulatório, ou seja, as radiodifusoras estão hoje submetidas ao mesmo conjunto de regras que foram aprovadas em 1962. Mesmo durante o regime militar de 1964 a $1985,{ }^{49}$ as regras para a indústria radiodifusora não experimentaram qualquer modificação estrutural. A única alteração significativa consistiu na exigência de edição da programação para controle da chamada "propaganda subversiva".

Em 1967, o Decreto-lei 236 tornou mais difícil a obtenção de concessões de radiodifusão no Brasil, bem como impôs limitações à múltipla propriedade de estações de radiodifusão, embora não limitasse a propriedade cruzada.

$\mathrm{O}$ art. $4^{\circ}$, do Decreto-lei citado determinou que os serviços de radiodifusão poderiam ser outorgados somente a empresas cujas ações ou cotas fossem subscritas integralmente por brasileiros natos. Existia, à época, uma forte razão para que se procedesse a esta alteração. Uma análise acurada da alteração mostra que ela se deveu ao poderoso lobby exercido pelas radiodifusoras brasileiras no Congresso em meados de 1950. Antes da edição do Decreto-lei 236, de 1967, as organizações Globo - o grupo radiodifusor então mais poderoso e influente no Brasil ${ }^{50}$ - tinham uma parceria com a Time Life, mas desejavam ver-se livres dela. O Decreto-lei, ao proibir que acionistas estrangeiros participassem do capital social de radiodifusoras interrompeu abruptamente a sociedade, beneficiando a Globo em detrimento dos investidores estrangeiros.

Uma situação semelhante ocorreu na década de 1970. Em particular, em 1974, para acomodar os interesses da Band, o Congresso aprovou a Lei 6.192, que vedou a discriminação entre brasileiros natos e naturalizados.

\footnotetext{
${ }^{49}$ Para um relato dos acontecimentos do período, vide: USTRA, Carlos Alberto Brilhante. (2007). A verdade sufocada. $5^{\text {a }}$ ed., Editora Ser: Brasília.

${ }^{50}$ As quatro maiores concessionárias de radiodifusão televisiva, no Brasil, são Globo, Record, SBT e Band. A Globo tinha uma receita líquida de mais de 5 bilhões de dólares em 2008 e representava cerca de $60 \%$ do total da audiência televisiva no Brasil.
}

Revista de Direito, Estado e Telecomunicações, v. 3, n. 1, p. 111-166 (2011)

DOI: https://doi.org/10.26512/lstr.v3i1.21669 


\section{O quadro constitucional para o conteúdo eletrônico no Brasil}

No contexto constitucional dos Estados Unidos, pode soar estranho que a Constituição brasileira trate detalhadamente do tema da comunicação social e eletrônica ${ }^{51}$ ou mesmo que essa matéria receba status constitucional. A Constituição brasileira de 1988 delineia o quadro regulatório da indústria de radiodifusão.

Até 1988 , a radiodifusão era compreendida como uma espécie de serviço de telecomunicações. Embora houvesse várias regras diferenciando a radiodifusão de outros serviços de telecomunicações, as radiodifusoras notaram que precisariam criar barreiras mais sólidas entre elas e a indústria de telecomunicações. A diferenciação era essencial para que as radiodifusoras mantivessem, por exemplo, isenções tributárias. Em um país como o Brasil, com a terceira maior carga tributária do mundo em telecomunicações,${ }^{52}$ as isenções tornaram-se da maior importância. Outra característica essencial que a indústria nacional de radiodifusão estava ansiosa por preservar dizia respeito à proteção contra investimento estrangeiro.

Quando a nova Constituição brasileira foi promulgada em 1988, muitas das provisões presentes no Decreto-lei de 1967 e no Código Brasileiro de Telecomunicações de 1962 foram incorporadas em seu texto. Assim, o lobby das radiodifusoras foi capaz de elevar as proteções da indústria ao nível constitucional. Os parágrafos que se seguem delineiam as principais previsões constitucionais a esse respeito e mostram como as radiodifusoras usaram-nas para promover sua agenda e influenciar os resultados da revolução convergente.

A Constituição brasileira de 1988 seguiu-se ao final do governo militar no país. É usualmente reconhecida como um documento bem escrito, embora a tentativa de abarcar um grande número de demandas de todos os atores sociais tenha resultado em uma Constituição extensa com 249 artigos. A indústria de telecomunicações foi nela referida com especial ênfase ao

\footnotetext{
${ }^{51} \mathrm{~A}$ exceção a esta regra geral está nas garantias da Constituição dos Estados Unidos sobre a liberdade de expressão e de manifestação do pensamento.

${ }^{52} \mathrm{~A}$ média percentual de tributes sobre serviços de telecomunicações, no Brasil, está acima de $43 \%$ e é uma das três maiores cargas tributárias do mundo. Vide: http://www.teleco.com.br/tutoriais/tutorialtrib/pagina_1.asp.
} 
serviço de radiodifusão. Este veio a ser tratado nos artigos 220 a 224 em um capítulo à parte sobre comunicação social.

As comunicações foram segmentadas em três indústrias principais: a) a indústria de radiodifusão, incluindo televisão e rádio; b) a imprensa escrita ou por outros meios; e c) a comunicação social eletrônica, referindo-se à mídia eletrônica distinta da televisão aberta, independentemente da tecnologia empregada. As regras constitucionais para a indústria de telecomunicações possuem um conjunto de consequências que são delineadas nos parágrafos seguintes.

Em primeiro lugar, a redação original do art. 222 dispunha que a propriedade das empresas de radiodifusão, inclusive estações de televisão e rádio, ou qualquer empresa de mídia impressa fosse exclusivamente de brasileiros natos ou naturalizados há mais de dez anos. A responsabilidade pela administração e orientação intelectual pertencia a brasileiros natos ou naturalizados.

Em segundo lugar, o parágrafo original do art. 222 proibia a participação de pessoas jurídicas no capital social de empresa jornalística ou de radiodifusão. Isto significava que somente particulares podiam se tornar seus sócios à exceção de pessoas jurídicas cujo capital pertencesse exclusiva e nominalmente a brasileiros. Dita proibição foi criada para impedir que grandes empresas - mesmo as brasileiras - competissem com a Globo, de propriedade familiar. Em 2002, devido a mudanças no cenário econômico, e com o apoio da ABERT, o Congresso brasileiro aprovou a Emenda Constitucional n. 36 para permitir que até $30 \%$ do capital total e do capital votante das empresas de radiodifusão pertencessem a pessoas jurídicas com participação estrangeira. Em qualquer hipótese, $70 \%$ do capital total e votante de radiodifusoras no Brasil devem pertencer a brasileiros natos ou naturalizados.

A emenda citada determinou caber a cidadãos brasileiros a gestão das atividades editoriais, incluindo decisões sobre a programação e seu conteúdo. Além disso, o art. 222 dispõe que os meios de comunicação social eletrônica, independentemente da tecnologia empregada, deverão observar os princípios de produção e programação aplicáveis às emissoras de rádio e televisão contidos no artigo anterior. Há um debate jurídico no Brasil sobre a extensão do significado do termo comunicação social. De um lado, há quem defenda que o termo deveria abarcar qualquer comunicação de um Revista de Direito, Estado e Telecomunicações, v. 3, n. 1, p. 111-166 (2011) DOI: https://doi.org/10.26512/lstr.v3i1.21669 
para dois ou mais receptores, enquanto outros defendem que o termo somente incluiria comunicações distribuídas por prestadores de serviços de radiodifusão ou telecomunicações com o objetivo de lucro.

Os princípios do art. 221 da Constituição brasileira sugerem que os prestadores de serviços de comunicação social eletrônica devam garantir, em suas programações: a) finalidades educativas, artísticas, culturais e informativas; b) promoção da cultura nacional e regional e estímulo à produção independente que objetive sua divulgação; c) regionalização da produção cultural, artística e jornalística, conforme percentuais estabelecidos em lei; e d) respeito aos valores éticos e sociais da pessoa e da família. O terceiro princípio é especialmente relevante, pois ele prevê a adoção de um sistema de cotas para distribuição de conteúdo, que pode afetar profundamente o mercado de distribuição de informação eletrônica no Brasil.

Finalmente, a Constituição garante a prioridade a profissionais brasileiros na execução de produções nacionais. O cancelamento da concessão ou permissão de radiodifusão, antes de vencido o prazo, somente pode ser feito por decisão judicial. A não renovação de concessão ou permissão de serviço de radiodifusão depende da aprovação de, no mínimo, dois quintos do Congresso Nacional, em votação nominal. A tabela a seguir (Tabela 2) elenca as obrigações aplicáveis à indústria de comunicações contidas na Constituição brasileira:

\begin{tabular}{|l|c|c|}
\hline Regras constitucionais & $\begin{array}{c}\text { Radiodifusoras } \\
\text { (rádio e televisão) }\end{array}$ & $\begin{array}{c}\text { Outros prestadores } \\
\text { de serviços de } \\
\text { comunicação social } \\
\text { eletrônica }\end{array}$ \\
\hline Limites ao investimento estrangeiro & $\begin{array}{c}\text { Vedação de qualquer } \\
\text { investimento direto }\end{array}$ & Não há limites ${ }^{53}$ \\
\hline $\begin{array}{l}\text { Limite de participação de pessoas } \\
\text { jurídicas de 30\% do capital total ou } \\
\text { votante }\end{array}$ & $\begin{array}{c}\text { Sim. Ao menos 70\% } \\
\text { do capital total e } \\
\text { votante devem ser de } \\
\text { brasileiros natos ou } \\
\text { naturalizados }\end{array}$ & Não \\
\hline Somente brasileiros natos ou & Sim & Não \\
\hline
\end{tabular}

${ }^{53}$ Há uma exceção notória a esta regra no art. $7^{\circ}$, da Lei do Cabo, que limita a 49\% a participação de capital estrangeiro em prestadoras de TV a cabo.

Revista de Direito, Estado e Telecomunicações, v. 3, n. 1, p. 111-166 (2011) 


\begin{tabular}{|l|l|c|}
\hline $\begin{array}{l}\text { naturalizados podem exercer a gestão } \\
\text { editorial }\end{array}$ & Sim & Sim \\
\hline $\begin{array}{l}\text { Prioridade a profissionais brasileiros na } \\
\text { execução de produções nacionais }\end{array}$ & Sim & Sim \\
\hline Princípios do art. 221 devem ser seguidos & Sim & Não \\
\hline $\begin{array}{l}\text { Apreciação obrigatória pelo Congresso } \\
\text { para outorga ou renovação }\end{array}$ & & \\
\hline
\end{tabular}

Tabela 2 - Regras constitucionais aplicáveis à radiodifusão e a outros serviços de distribuição de sons e imagens no Brasil

Como é demonstrado na tabela acima, o serviço de radiodifusão, no Brasil, está sujeito a um conjunto de regras rigorosas quando em comparação com a relativa liberdade vivenciada pela indústria de distribuição de conteúdo eletrônico. Serviços como a TV a cabo, a TV por satélite, distribuição de conteúdo por telefones celulares e o acesso a conteúdo de mídia pela internet sofrem um menor grau de controle.

A presença de regras mais rigorosas para a indústria radiodifusora não é incomum no seio internacional, em especial, as relativas a limitações a investimentos estrangeiros. Nos Estados Unidos, a Seção 310 do Communications Act de 1934 impõe limites sobre a propriedade de estações de radiodifusão. Nenhuma licença de radiodifusão é outorgada a ou mantida por: a) qualquer estrangeiro ou seu representante legal; b) qualquer sociedade comercial constituída sob as leis de um país estrangeiro; c) qualquer sociedade comercial em que mais de 1/5 do capital social total ou votante seja de estrangeiros, seus representantes, representantes de governo estrangeiro, ou por qualquer empresa constituída sob as leis de outro país; d) qualquer sociedade comercial direta ou indiretamente controlada por outra sociedade comercial em que mais de $1 / 4$ do capital social total ou votante seja de estrangeiros, seus representantes, representante de governo estrangeiro, ou por qualquer sociedade comercial constituída sob as leis de outro país se a FCC considerar que o interesse público será preservado pela recusa ou revogação de tal licença.

Embora a última restrição se refira a sociedades comerciais, a FCC a aplica a qualquer espécie de pessoa jurídica. ${ }^{54}$ Sob essa rubrica, a FCC pode

${ }^{54}$ KENNEDY, Charles H. (2001). An Introduction to US Telecommunications Law. $2^{\mathrm{a}}$ ed., Norwood, MA: Artech House, p. 203.

Revista de Direito, Estado e Telecomunicações, v. 3, n. 1, p. 111-166 (2011)

DOI: https://doi.org/10.26512/lstr.v3i1.21669 
negar uma licença de radiodifusão de TV ou rádio a qualquer entidade direta ou indiretamente controlada por outra empresa nacional caso esta seja controlada por estrangeiros em mais de 1/4 do capital social total ou votante, inclusive seus representantes, um governo estrangeiro ou uma empresa estrangeira.

A FCC aplica estas restrições a qualquer espécie de pessoa jurídica, inclusive associações e consórcios. Outro mecanismo utilizado pela Comissão para diminuição do interesse de um ente estrangeiro em uma licença é a aplicação de um multiplicador. O multiplicador permite que a FCC meça o grau de investimento estrangeiro efetivo que uma entidade exerce sobre um licenciado. ${ }^{55}$

Alguns estudiosos defendem que as razões que justificaram a aprovação da Seção 310(b) do Communications Act de 1934, ou seja, segurança nacional, que poderia ser ameaçada pelo controle de estações de rádio dos Estados Unidos por estrangeiros seriam hoje anacrônicas, em especial em uma era de crescente convergência e globalização.

A batalha do conteúdo eletrônico: a agenda não tão secreta das radiodifusoras brasileiras

\section{O contexto da disputa}

À medida que a convergência avança e os preços de produtos convergentes diminuem devido às economias de escala, o conflito de plataformas diferentes pela distribuição de conteúdos eletrônicos semelhantes torna-se muito provável. A percepção, pelo público em geral, da diversidade de serviços como um produto único reforça o fenômeno da convergência e acelera o ciclo de integração.

No Brasil, o conflito inevitável entre as diferentes plataformas que disputam o mesmo conteúdo tomou forma no Projeto de Lei 29/2007, da Câmara dos Deputados, mais tarde convertido no Projeto de Lei da Câmara 116/2010, no Senado Federal. Este projeto define, de forma unificada, a regulação sobre os meios de comunicação social, mídia e conteúdo eletrônico, à exceção da indústria de radiodifusão. Em outras palavras, o

${ }^{55}$ KENNEDY, Charles H. Op. cit., p. 204.

Revista de Direito, Estado e Telecomunicações, v. 3, n. 1, p. 111-166 (2011)

DOI: https://doi.org/10.26512/1str.v3i1.21669 
projeto se aplica a todas as plataformas que distribuem conteúdo eletrônico, incluindo algumas partes do conteúdo pela internet, ao menos indiretamente.

O projeto de lei citado se aplica ao conteúdo eletrônico baixado em celulares, informação paga acessada pela internet e dados oferecidos por qualquer tipo de assinatura televisiva (cabo ou satélite). Com isso, o projeto de lei pode ser visto, por diversos ângulos, como um esforço claro das radiodifusoras brasileiras para restringir o livre fluxo de conteúdo eletrônico e criar amarras para a produção e distribuição de conteúdo de mídia eletrônica por plataformas competitivas, em especial por aquelas da internet e TV a cabo.

Uma das principais finalidades do projeto de lei citado é a de concretizar as tão esperadas aspirações da indústria de radiodifusão, mediante a extensão de alguns de seus ônus regulatórios para outras plataformas de distribuição que possam competir diretamente com as radiodifusoras pela propaganda comercial e, por isso, representam uma ameaça ao seu modelo de negócios. No trecho que se segue, analisa-se detidamente as principais tentativas das radiodifusoras de firmarem uma posição dominante na distribuição de conteúdo eletrônico no Brasil.

Embora o projeto de lei citado não tenha ainda sido aprovado pelo Congresso Nacional brasileiro, ele é considerado ${ }^{56}$ uma peça de importância fundamental no contexto da atual disputa sobre o conteúdo, na medida em que torna explícitas as intenções e propostas da indústria da radiodifusão para o cenário de conteúdo eletrônico brasileiro.

Em síntese, as principais disposições do PLC 116/2010 estão elencadas abaixo:

a) a criação do serviço de acesso condicionado, que é definido como um serviço de telecomunicações para a fornecimento de conteúdo eletrônico a assinantes por intermédio da oferta de pacotes ou canais por qualquer tecnologia eletrônica.

\footnotetext{
${ }^{56}$ O PL 29/2007 foi aprovado em 2010 na Câmara dos Deputados e está atualmente sob análise das comissões do Senado Federal. Ele goza de forte apoio por parte de muitos atores industriais e, ceteris paribus, deve ser, em breve, transformado em lei. 
b) a criação de quatro categorias de atividades a serem desempenhadas pelo novo serviço de acesso condicionado: ${ }^{57}$ a produção/criação, a programação, o empacotamento e a distribuição de conteúdo aos assinantes; ${ }^{58}$

c) bloqueio das operadoras de telecomunicações da possibilidade de adquirir os direitos para transmissão de eventos de interesse nacional, o direito de contratação de artistas famosos e os direitos de possuírem copyrights de obras nacionais, em geral;

d) nos canais de espaço qualificado, ${ }^{59}$ ao menos três horas e meia por semana do "horário nobre de televisão" - de 18:00 à meia-noite são destinadas a produtores independentes de conteúdo. Em outras palavras, todas os canais de TV a cabo que transmitem principalmente filmes ou sérias televisivas, como o $\mathrm{HBO}$, devem colocar no ar três horas e meia de produções de conteúdo independente entre 18:00 e meia-noite toda semana. Além disso,

${ }^{57} \mathrm{O}$ serviço de acesso condicionado é o nome utilizado para designar todos os serviços de distribuição de conteúdo eletrônico para assinantes pagantes.

${ }^{58}$ A redação final do PL 29/2007 aprovada na Câmara dos Deputados define separadamente cada uma destas atividades: a) a produção é definida como "atividade de elaboração, composição, constituição ou criação de conteúdos audiovisuais em qualquer meio de suporte"; b) a programação é definida como "atividade de seleção, organização ou formatação de conteúdos audiovisuais apresentados na forma de canais de programação, inclusive nas modalidades avulsa de programação e avulsa de conteúdo programado"; c) o empacotamento é definido como "atividade de organização, em última instância, de canais de programação, inclusive nas modalidades avulsa de programação e avulsa de conteúdo programado, a serem distribuídos para o assinante"; e d) a distribuição é definida como "atividades de entrega, transmissão, veiculação, difusão ou provimento de pacotes ou conteúdos audiovisuais a assinantes por intermédio de meios eletrônicos quaisquer, próprios ou de terceiros, cabendo ao distribuidor a responsabilidade final pelas atividades complementares de comercialização, atendimento ao assinante, faturamento, cobrança, instalação e manutenção de dispositivos, entre outras".

${ }^{59}$ A redação final do PL 29/2007 aprovada na Câmara dos Deputados define o espaço qualificado como "espaço total do canal de programação, excluindo-se conteúdos religiosos ou políticos, manifestações e eventos esportivos, concursos, publicidade, televendas, infomerciais, jogos eletrônicos, propaganda política obrigatória, conteúdo audiovisual veiculado em horário eleitoral gratuito, conteúdos jornalísticos e programas de auditório ancorados por apresentador". 
metade deste conteúdo deve ser gerado por produtores independentes brasileiros. ${ }^{60}$

e) na programação, todos os prestadores de serviço de acesso condicionado devem oferecer pacotes nos quais, para cada três canais com programas de espaço qualificado, ao menos um seja brasileiro. Disto se deduz que ao menos $1 / 3$ do conteúdo deva ser programado por um produtor de conteúdo brasileiro.

f) as entidades distribuidoras e empacotadoras não podem, diretamente ou através de suas subsidiárias, inserir qualquer publicidade ou conteúdo em programas sem autorização prévia e expressa do seu programador ou produtor.

g) o distribuidor de conteúdo eletrônico que se qualifique como um prestador de serviço de acesso condicionado deve comprometer-se a cumprir as mesmas obrigações de transporte de canais exigidas da TV a cabo. Em outras palavras, o distribuidor deve transportar o sinal da radiodifusão sem modificação, ao mesmo tempo em que deve disponibilizar um canal para cada uma das seguintes entidades: a Câmara dos Deputados; o Senado Federal; o Supremo Tribunal Federal; o Poder Executivo, para sua emissora oficial, para prestação de serviços de radiodifusão pública por ele próprio como instrumento de universalização dos direitos à informação, à comunicação, à educação e à cultura, e para um canal educativo e cultural; a sociedade, para um canal comunitário de utilização livre e compartilhada por entidades não governamentais e sem fins lucrativos e para um canal de cidadania destinado à transmissão de programações das comunidades locais e divulgação de atividades

\footnotetext{
${ }^{60}$ A redação final do PL 29/2007 aprovada na Câmara dos Deputados entende por produtora brasileira independente a "produtora brasileira que atenda os seguintes requisitos, cumulativamente: a) não ser controladora, controlada ou coligada a programadoras, empacotadoras, distribuidoras ou concessionárias de serviço de radiodifusão de sons e imagens; b) não estar vinculada a instrumento que, direta ou indiretamente, confira ou objetive conferir a sócios minoritários, quando estes forem programadoras, empacotadoras, distribuidoras ou concessionárias de serviços de radiodifusão de sons e imagens, direito de veto comercial ou qualquer tipo de interferência comercial sobre os conteúdos produzidos; c) não manter vínculo de exclusividade que a impeça de produzir ou comercializar para terceiros os conteúdos audiovisuais por ela produzidos".
}

Revista de Direito, Estado e Telecomunicações, v. 3, n. 1, p. 111-166 (2011)

DOI: https://doi.org/10.26512/lstr.v3i1.21669 
dos poderes públicos federal, estadual e municipal; o Poder Legislativo municipal e estadual; e a academia, mediante canal universitário de uso compartilhado de instituições de ensino superior.

h) todos os prestadores de serviços de acesso condicionado, incluindo a possibilidade de assim serem classificados os que se utilizem da internet a depender da redação final da lei, serão legalmente considerados serviços de telecomunicações, o que, no contexto brasileiro implica em alta carga tributária; ${ }^{61}$

i) a competência para aplicação das regras de programação e empacotamento do projeto de lei citado foram atribuídas à ANCINE, enquanto a competência para outorga de autorizações do serviço, dentre outras, permanece com a Anatel. Tal fragmentação de competência não existe nos Estados Unidos, que mantêm ambas as responsabilidades sobre conteúdo e telecomunicações sob o manto da FCC.

A partir dos dispositivos elencados acima, que consistem em apenas uma parte do PLC 116/2010, é fácil perceber-se os efeitos de grande alcance que tais regras podem ter de imediato sobre a indústria de telecomunicações e sobre a distribuição de serviços de telecomunicações de conteúdo. Nas páginas seguintes, procura-se analisar as consequências de tais dispositivos.

\section{Limitações sobre conteúdo da internet}

Um dos dispositivos mais relevantes do PLC 116/2010 é a clara exceção de sua aplicação sobre a indústria de radiodifusão. Em versões anteriores do projeto de lei, a internet também vinha expressamente excluída. Dita exclusão, todavia, foi suprimida do texto atual e, à semelhança de qualquer outro plataforma que distribui conteúdo eletrônico e que requer assinatura paga para acesso, a internet pode ser considerada um serviço de acesso condicionado na linguagem do projeto de lei. Este novo serviço de acesso

${ }^{61}$ Caso a redação final da lei a ser aprovada insira a internet no seu escopo, a atualmente reduzida incidência de impostos sobre serviços de vídeo nela praticados sofrerá aumento considerável pela incidência do ICMS. Em outra frente, outros custos decorrentes da atividade de poder de polícia da Anatel também acrescentariam um ônus significativo sobre as atividades de mídia pela internet. 
condicionado inclui todos os serviços de telecomunicações que distribuem conteúdo eletrônico. Não obstante, é importante deixar claro que a aplicabilidade do projeto de lei à internet ainda é uma questão em aberto. De fato, até o momento, há propostas de redação que expressamente excluem o conteúdo da internet do escopo da lei.

A título de argumentação, consideremos por um momento que o projeto de lei citado tenha sido aprovado com sua redação atual. Neste caso, as consequências da aplicação das regras da lei em parte à internet - a parte em que o conteúdo é acessado por assinatura paga - ainda depende de esclarecimento. À primeira vista, os efeitos podem ser devastadores para a livre circulação da informação e de ideias na internet. A norma também parece entrar em choque com modelo de negócios da internet, que está assentado nos ideais de contratos privados e não-intervenção governamental.

Para se ter uma melhor compreensão da extensão do impacto tratado, é necessário um exemplo. Se o YouTube passasse a exigir registro formal, um valor de assinatura ou o conhecimento de regras predeterminadas antes que se assista a um vídeo, ele seria considerado um serviço de acesso condicionado sob a linguagem do PLC 116/2010. Se assim fosse, o YouTube seria considerado um prestador de serviço de acesso condicionado e, com isso, seria obrigado a observar todas as regulamentações pertinentes. Neste caso, o YouTube seria obrigado a ofertar 3 horas e meia de conteúdo brasileiro independente nos canais de espaço qualificado no horário nobre. O YouTube também teria que disponibilizar vídeos e canais de transporte obrigatório. Como um provedor de internet, o YouTube hoje paga 5\% de imposto sobre serviços no Brasil. Este imposto seria aumentado para 25\% no caso destes serviços serem considerados serviços de telecomunicações. Aparentemente, as consequências da aplicação direta da possível lei seriam absurdas e teriam efeitos devastadores na indústria em geral e nas empresas em particular.

Não obstante o absurdo descrito, seria exatamente isso que ocorreria na internet caso parte de seu conteúdo se enquadrasse no âmbito de aplicação da regulamentação de acesso condicionado. $\mathrm{O}$ fenômeno da convergência tende a embaçar as fronteiras dos diversos serviços. À medida que sítios eletrônicos passam a, cada vez mais, se assemelharem com a TV a cabo e a ofertarem acesso restrito de conteúdo eletrônico, a internet tornar-se-á tão regulada quanto as demais mídias de hoje.

Revista de Direito, Estado e Telecomunicações, v. 3, n. 1, p. 111-166 (2011)

DOI: https://doi.org/10.26512/lstr.v3i1.21669 
A internet regulada por dispositivos contidos no PLC 116/2010 tornarse-ia uma mídia bem diferente da de hoje. Esse cenário suscitaria novos desafios específicos próprios à internet. Um deles decorreria do caráter transnacional da internet. Como que a regulação e a aplicação do PLC 116/2010 pode ser implementada? O que aconteceria se um sítio eletrônico internacional oferecesse acesso restrito a conteúdo e observasse as condições estabelecidas? Se se tratasse de um provedor de serviço de conexão à internet (PSCI) que cobrasse pelo acesso à internet, que, por sua vez, permitisse o acesso ao conteúdo eletrônico. Nesse caso, o PSCI seria ele mesmo responsável por prestar o serviço de acesso condicionado? Essa responsabilidade seria imposta sobre os sítios eletrônicos onde tais conteúdos se localizassem?

Estas e outras questões deverão ser respondidas para garantir uma avaliação abrangente dos impactos que dita lei pode ter sobre o ambiente da internet. O que é certo é que a aplicação irrestrita do PLC 116/2010 à internet lhe daria nova forma e alteraria algumas das características fundamentais da rede mundial de computadores como ela é hoje entendida.

\section{Restrição à propriedade estrangeira}

A postura regulatória brasileira sobre conteúdo eletrônico é tradicionalmente protecionista, advinda de uma compreensível preocupação sobre a segurança nacional. A preocupação governamental sobre segurança resulta na criação de barreiras à livre prestação do serviço de radiodifusão. No Telecommunications Act de 1996, o Congresso norte-americano procurou aumentar a competição na indústria de telecomunicações e, apesar disso, não retirou as limitações a estações radiodifusoras. ${ }^{62}$ No Brasil, por outro lado, as limitações à propriedade estrangeira entraram em vigor em 1967, quando as radiodifusoras nacionais enfrentaram a competição estrangeira, em especial do grupo Time Life.

Hoje, há dois tipos de limitações à propriedade no setor de telecomunicações brasileiro. $\mathrm{O}$ primeiro tipo diz respeito às restrições

${ }^{62}$ PRADO, Paola. (2008). Foreign Ownership of Broadcast Television Stations in the Digital Era. Artigo apresentado no National Communications Association realizado em San Diego, p. 2. Vide: http://www.allacademic.com $/ / \mathrm{meta} /$ p_mla_apa_research_citation/2/5/8/8/0/pages258802/p258802-1.php. 
impostas sobre a propriedade estrangeira, enquanto o segundo tipo se refere às restrições sobre propriedade cruzada de mídias distintas, como, por exemplo, a proibição de controle, por uma mesma empresa, de uma concessionária de telefonia e de uma prestadora de TV a Cabo. Como regra, o segundo tipo de limitações à propriedade têm sido progressivamente relaxado. Nos Estados Unidos, a FCC suspendeu as limitações antes existentes sobre a propriedade de jornais e estações de TV no mesmo mercado. ${ }^{63}$

No Brasil, vivencia-se um longo debate, que tem sinalizado o fim das restrições à propriedade estrangeira no serviço de TV a Cabo. ${ }^{64}$ Esse debate deve ser analisado tendo-se em conta a proibição de operação da TV a cabo, no Brasil, por empresas de telecomunicações. Nesse cenário, o PLC 116/2010 representa uma negociação que permite às concessionárias de telefonia prestar serviços de TV a cabo, mas limita o conteúdo estrangeiro e cria restrições ao livre mercado.

Dessa forma, as consequências do PLC 116/2010 para empresas estrangeiras, se mantida a redação atual, serão as seguintes: a) as concessionárias de telefonia fixa sob controle estrangeiro poderão prestar serviços de TV a cabo; b) o conteúdo produzido por empresas estrangeiras dará espaço ao conteúdo nacional nas condições previstas no PLC 116/2010; c) as empresas estrangeiras de telecomunicações não poderão controlar mais que $30 \%$ do total das ações de empresas que produzam conteúdo; d) empresas estrangeiras distribuidoras de conteúdo não poderão contratar artistas brasileiros ou adquirir a propriedade de direitos de imagem de trabalhos nacionais.

\section{Cotas de conteúdo no Brasil e nos Estados Unidos}

O sistema de cotas de conteúdo eletrônico descrito no PLC 116/2010 representa o abandono de práticas correntes do modelo regulatório brasileiro. Até o presente, o arcabouço normativo brasileiro tem regulado principalmente infraestrutura, deixando que o mercado lide, em grande

\footnotetext{
${ }^{63}$ Vide: http://www.law.com/jsp/cc/PubArticleCC.jsp?id=1202444940642. ${ }^{64}$ No Brasil, o art. $7^{\circ}$, da Lei 8.977/1995 limita o investimento estrangeiro a $49 \%$ do total do capital social com direito a voto.

Revista de Direito, Estado e Telecomunicações, v. 3, n. 1, p. 111-166 (2011)

DOI: https://doi.org/10.26512/lstr.v3i1.21669
} 
medida, com questões de conteúdo. A Constituição de 1988, entretanto, abriu uma janela para a regulação direta de conteúdo eletrônico. ${ }^{65}$

Dita questão foi transformada em uma questão constitucional, embora ainda não haja pronunciamento judicial de peso sobre tema, no Brasil, sobre a constitucionalidade de se estabelecerem cotas de conteúdo nacional, tendo-se também em conta a proteção à liberdade de expressão e de manifestação do pensamento previstas no art. $5^{\circ}$, da Constituição de 1988. Ao menos no que diz respeito à passagem do PL 29/2007 e PLC 116/2010 pelas diversas comissões do Congresso Nacional, os defensores do sistema de cotas estão bem protegidos sob uma perspectiva constitucional.

Nos Estados Unidos, por outro lado, um sistema de cotas seria tido por inconstitucional por violação ao princípio da liberdade de manifestação do pensamento. Tal sistema poderia ser percebido como limitação a priori [prior constraint].$^{66}$ Por limitação $a$ priori entende-se o risco de não se fazer aquilo que o governo dita que a mídia distribua ou publique. No caso do PLC 116/2010, isto levaria a multas pesadas e ao risco de perda da outorga do serviço. O professor Barron explica que, embora a mídia em si mesma constitua uma barreira à diversidade, o problema daí gerado pode ser solucionado mediante a implementação de remédios, tais como a fixação do direito de compra de espaço publicitário de forma não discriminatória ou o direito de resposta por personalidades públicas ou por ocupantes de cargos públicos. ${ }^{67}$

Mesmo nos Estados Unidos, entretanto, tem-se o entendimento cristalizado de que as garantias da Emenda n. 1 são mais fortes para a imprensa do que para a radiodifusão, ${ }^{68}$ como se pode ver no caso Tornillo $v$. Miami Herald. ${ }^{69} \mathrm{O}$ fundamento para o tratamento diferenciado entre radiodifusoras e outras mídias decorre do maior potencial de penetração da

${ }^{65}$ CARVALHO, Alberto Arons [et al.]. (2003). Direito da comunicação social. Lisboa: Notícias Editorial, p. 47.

${ }^{66}$ TEETER, Dwight L. [et al.]. (2008). Law of Mass Communications: Freedom and Control of Print and Broadcast Media. New York: Foundation Press, p. 92. ${ }^{67}$ BARRON, Jerome A. (1973). Freedom of the Press for Whom? Right of Access to Mass Media. Bloomington: Indiana University Press, p. 6.

${ }^{68}$ TEETER, Dwight L. [et al.] (2008). Law of Mass Communications: Freedom and Control of Print and Broadcast Media. New York: Foundation Press, p. 95.

${ }^{69}$ Tornillo v. Miami Herald Pub. Co., 287 So.2d 78 (Fla.1973). 
radiodifusão. Por isso, o PLC 116/2010 delineia um sistema detalhado e complexo de cotas aplicável ao conteúdo eletronicamente distribuído por dispositivos móveis, TV a cabo e internet. Os principais argumentos defendidos pelos fautores do sistema de cotas são: a) a diversidade é necessária se se objetiva um melhor nível de informação à população; b) os incentivos para produtores nacionais de conteúdo trarão benefícios econômicos para a indústria nacional; c) a posição dominante de provedores de conteúdo estrangeiros representa um risco à identidade nacional brasileira; d) o sistema de cotas é a melhor forma de valorizar os trabalhadores/atores/produtores nacionais; e) a mídia é controlada por uma visão unitária, quando a existência de alternativas é desejável; f) a abundância de conteúdo nacional disponível fará com que caia o preço de acesso a tais conteúdos.

Tais argumentos têm sido usados para justificar a imposição do sistema de cotas na distribuição de conteúdo eletrônico na internet, nos serviços de TV a cabo e no conteúdo acessado por aparelhos celulares e outros dispositivos móveis.

Para se ter uma visão clara dos prós e contras, é vital examinar-se a força do discurso sobre a 'diversidade de conteúdo'. Quanto mais diversificado o conteúdo acessado por uma pessoa, mais informada ela será. Essa ratio é fortemente questionada por Richard Posner, ${ }^{70}$ que defende que a sempre crescente variedade de distribuição de conteúdo, que se originara do aumento da competição derivada de custos menores de comunicação, teria criado uma maior polarização, sensacionalismo e desconfiança sobre os meios de comunicação. Posner explica que, em decorrência do aumento da competição, a mídia tende a se desviar de seu caráter informativo e da verdade para se concentrar no sensacionalismo. Na batalha por audiência, surge uma forte inclinação à polarização política e ao recrudescimento do conflito. Em virtude de tal circunstância, é de se considerar se um meior número de meios de informação é melhor para audiência.

Ainda, é necessário levar em conta o lado econômico da questão. Estudos recentes mostram que a indústria do conteúdo eletrônico é estruturada em uma cadeia que torna difícil simplesmente firmarem-se

\footnotetext{
${ }^{70}$ Vide: http://www.nytimes.com/2005/07/31/books/review/31POSNER.html. 
regras para os seus elos sem que isso resulte em efeitos adversos no restante da cadeia. Essa cadeia consiste na produção, programação, empacotamento e distribuição do conteúdo. ${ }^{71} \mathrm{O}$ sistema de cotas de conteúdo sobrecarrega um dos elos da cadeia: a distribuição de conteúdo ao público. De acordo com estudos prévios, ${ }^{72}$ é altamente provável que se tenha uma perda de $20 \%$ de mercado de assinantes pela indústria de TV a cabo para os três primeiros anos após a implementação do sistema de cotas. Como foi dito na introdução a este artigo, o mercado de TV a cabo já deveras limitado pode não ter condições de suportar um impacto de larga escala como este. $\mathrm{O}$ custo marginal para implementação do sistema de cotas proposto no PLC $116 / 2010$ atingiria 0,42 bilhões de dólares no primeiro ano e outros 0,88 , 1,25 e 1,7 bilhões de dólares para os três anos seguintes. Ainda, os preços médios da TV a cabo, no Brasil, teriam um aumento de aproximadamente $82,6 \%$ nos quatro anos seguintes à adoção do sistema de cotas.

Em todo o mundo, experiências semelhantes levaram a resultados semelhantes. As experiências canadense e australiana de fixação de cotas de conteúdo mostram que a introdução de dito sistema teve impactos negativos quase imediatos no custo da programação da TV a cabo, seguidos da redução do número de assinantes. ${ }^{73} \mathrm{Na}$ Austrália, dois anos após a adoção do sistema de cotas, o aumento do preço da TV por assinatura resultou em um crescimento negativo de mercado da ordem de $0,3 \%$. No ano anterior à adoção do sistema de cotas, o mesmo mercado havia tido um crescimento positivo de $16 \%$.

No Canadá, onde o sistema de cotas foi adotado em 1999, o mercado de TV paga sofreu uma considerável queda no número de assinantes daquele ano em diante. Cinco anos após a implementação do sistema de cotas, em 2004, o mercado de TV paga, no Canadá, contraiu para $75 \%$ de sua base original em 1999. Estes e outros exemplos demonstram os fortes efeitos que a adoção do sistema de cotas de conteúdo pode ter sobre a indústria de

\footnotetext{
${ }^{71}$ Apresentação feita ao Conselho Administrativo de Defesa Econômica (CADE) por Manoel Rangel, intitulada "Desafios para a regulação do conteúdo audiovisual no ambiente convergente".

${ }^{72}$ TUROLLA, Frederico Araujo. (2008). Impactos econômicos das cotas e desestímulo ao capital estrangeiro no mercado brasileiro de TV por assinatura. São Paulo: Pezco Pesquisa e Consultoria.

${ }^{73}$ Vide: http://www.screenaustralia.gov.au/gtp/wptvprofit.html.
} 
conteúdo eletrônico. Além disso, tendo por base o resultado sobre o setor de TV paga, é razoável considerar-se que os efeitos seriam ainda mais graves sobre o ambiente da internet.

Embora os efeitos de uma política de cotas de conteúdo agressiva possam ser devastadores, não se quer dizer com isso que qualquer variação de tal política terá os mesmos resultados negativos. A Constituição brasileira parece permitir a adoção de um sistema de cotas de conteúdo para a proteção do conteúdo nacional ${ }^{74}$, que teria que ser implementado, todavia, de forma mais moderada para não afligir os princípios da liberdade de expressão e do direito de informar e de acesso à informação. ${ }^{75}$

Sob a perspectiva do direito norte-americano, dita proteção teria mais dificuldade de ser considerada constitucional, tendo-se em vista o conflito com a Emenda n. 1. Sobre esse aspecto, é apropriado analisar a opinião de Cass Sustein sobre o tema. ${ }^{76}$ Em primeiro lugar, Sunstein argumenta que existem duas tradições de liberdade de expressão nos Estados Unidos. Uma delas assentada na ênfase ao bom funcionamento do mercado de manifestação do pensamento [well-functioning speech market] enquanto a outra se assenta na deliberação pública.

A primeira das tradições se originou do mercado de ideias [marketplace of ideas $]^{77}$ apresentado pelo juiz Holmes, da Suprema Corte, quando da decisão de anulação do direito de resposta no caso Miami Heraldo Pun. v. Tornillo e da decisão da FCC sobre paridade de tratamento das notícias por parte das radiodifusoras [fairness doctrine $]{ }^{78} \mathrm{~A}$ segunda das tradições

${ }^{74} \mathrm{O}$ discurso da proteção do conteúdo nacional ser posto em perspectiva. No Canadá, por exemplo, há reclamações constantes sobre a preferência que as radiodifusoras sempre dão aos mesmos artistas canadenses. Vide http://www.mapleleafweb.com/ features/canada-radio-television-and-telecommunications-commission.

${ }^{75}$ Tais princípios estão previstos no art. $5^{\circ}$, incisos IX e XIV, da Constituição brasileira de 1988.

${ }^{76}$ SUNSTEIN, Cass. (1995). The First Amendment in Cyberspace. In: Yale Law Journal 104: 1757.

${ }^{77}$ De acordo com Holmes, as manifestações do pensamento somente poderiam ser reguladas no caso de um perigo iminente e evidente, sem o que qualquer restrição à liberdade de expressão seria, em princípio, inválida. Vide: Abrams v. United States, 250 U.S. 616 (1919).

${ }^{78}$ Syracuse Peace Council v. Television Station WTVH, 2 FCC Rcd. 5043, 5054-55 (1987).

Revista de Direito, Estado e Telecomunicações, v. 3, n. 1, p. 111-166 (2011)

DOI: https://doi.org/10.26512/lstr.v3i1.21669 
associa a ideia da liberdade de expressão aos ideais de deliberação democrática, em que se rechaça a existência de monopólio e se considera que a atuação governamental para incentivo da diversidade e da abordagem de questões de interesse público não feriria o princípio da liberdade de expressão. ${ }^{79}$ Pode-se facilmente perceber que as duas tradições de liberdade de expressão são, até certo ponto, contraditórias e estão em tensão permanente.

Sunstein propõe, todavia, a possibilidade de reconciliação de tais tradições em casos concretos. Assim, Sunstein sustenta que algum grau de regulação sobre o discurso seria aceitável nos seguintes casos concretos: regulação para assegurar a competição nos novos mercados de comunicação; regulação para subsidiar certas tecnologias consideradas pelo regulador como tecnologias de futuro promissor; regulação para subsidiar determinados programas sobre temas infantis e governamentais; regulação para assegurar canais abertos para quem, de outro modo, não poderia acessálos; regulação para assegurar o acesso universal dos consumidores às redes; regulação para proteção contra mensagens ou programas obscenos, difamatórios, violentos, comerciais ou de assédio; regulação sobre conteúdo para garantir a transmissão de programas educacionais e governamentais.

Levando em conta os argumentos de Sunstein, pode-se defender que o sistema de cotas de conteúdo proposto no PLC 116/2010 se enquadraria sob a categoria da regulação para assegurar canais abertos para quem, de outro modo, não poderia acessá-los. O argumento de Sunstein para justificar esta regulação tem duas partes. Em primeiro lugar, ele defende que, no caso em que uma determinada detentora de infraestrutura essencial de transporte de comunicações tivesse espaço para canais ainda não preenchidos, o governo poderia obrigá-la a alocá-los para outras estações que não pudessem pagar pelo transporte do sinal. Sunstein argui que esta abordagem não feriria a regra da Emenda n. 1. Em segundo lugar, Sunstein sugere que seria lícito que o governo exigisse das empresas detentoras de infraestrutura essencial de transporte de comunicações que elas separassem certos canais para serem

${ }^{79}$ Isto seria verdade mesmo se a atuação governamental resultasse na implementação de mecanismos de controle sobre os proprietários das plataformas de mídia. Vide Red Lion Broadcasting Co. v. Fcc, 395, U.S. 367 (1969). 
preenchidos por um método randômico. ${ }^{80}$ Isto também não representaria qualquer transgressão à Emenda n. 1, segundo Sunstein. ${ }^{81}$ À luz dos argumentos de Sunstein, o sistema de cotas de conteúdo poderia ser considerado legítimo no arcabouço regulatório norte-americano.

No caso Turner Broadcasting v. FCC, ${ }^{82}$ todavia, a Suprema Corte decidiu que as regras de obrigatoriedade de transporte de canais respeitariam a Emenda n. 1, desde que fossem neutras quanto ao conteúdo. Além disso, um dos argumentos centrais foi a proteção de lares que não detinham serviço de cabo da perda do serviço regular de radiodifusão, que seria a consequência lógica no caso da inexistência de regras de distribuição obrigatória [must-carry rules]. O juiz Kennedy, da Suprema Corte, responsável pelo voto vencedor, observou que "uma regulação neutra quanto ao conteúdo é possível perante a Emenda n. 1 se ela protegesse interesses governamentais relevantes não correlatos à supressão da liberdade de expressão e se não onerasse substancialmente o discurso mais do que o necessário para promoção de tais interesses". ${ }^{83}$

Dessa forma, no contexto jurídico norte-americano, um sistema de cotas de conteúdo somente seria defensável se ele preenchesse duas condições: proteção de interesses governamentais relevantes não relacionados à supervisão da liberdade de expressão; e que o ônus daí decorrente não fosse mais do que o necessário à proteção de tais interesses. Na prática, entretanto, embora a FCC tenha sempre envidado esforços para melhoria do serviço de radiodifusão, ela não interfere com as práticas de programação das estações em específico.

\footnotetext{
${ }^{80}$ BENJAMIN, Stuart Minor [et al.]. (2006). Telecommunications Law and Policy. Durham, NC: Carolina Academic Press, p. 618.

${ }^{81}$ É importante notar que Cass Sustein retira este argument do voto divergente da juíza da Suprema Corte, Sandra O'Connor, no caso Turner. Vide Turner Broadcasting v. Federal Communications Commission, 512 U.S. 622 (1994). Este caso é conhecido como Turner I.

${ }^{82}$ Turner Broadcasting System v. FCC, 520 U.S. 180, 117 S.Ct. 1174 (1997). O caso é conhecido como Turner II.

${ }^{83}$ Vide página $10 \mathrm{em}$ : http://docs.justia.com/cases/supreme/520/180.pdf.

Revista de Direito, Estado e Telecomunicações, v. 3, n. 1, p. 111-166 (2011)

DOI: https://doi.org/10.26512/lstr.v3i1.21669
} 


\section{Diferenças básicas entre radiodifusoras e outras indústrias}

O artigo já discutiu algumas características técnicas que, tomadas em seu conjunto, diferenciam a radiodifusão de outros serviços eletrônicos de conteúdo. É apropriado, agora, retomar tais características. ${ }^{84}$

Tais características não são, por si só, suficientes para justificar a assimetria regulatória dos serviços de radiodifusão. As características acima não mostram senão as diferenças entre a radiodifusão e outros serviços de transmissão de informação. A questão aqui é porque a radiodifusão é diferente? Porque ela merece um tratamento diferenciado? Em outras palavras, porque há a necessidade de uma regulação mais rigorosa sobre a radiodifusão em comparação com outros serviços de conteúdo eletrônico? A resposta a esta questão determina o futuro da batalha sobre conteúdo na mídia eletrônica. As alternativas são deveras simples.

Se a radiodifusão não for considerada suficientemente diferenciada para exigir uma regulação em separado, dois cenários possíveis podem se

\footnotetext{
${ }^{84}$ São elas: a) seu conteúdo é definido pela radiodifusora;b) a radiodifusora é responsável pelos conteúdos transmitidos; c) o conteúdo é transmitido pelo espectro para dois ou mais dispositivos simultaneamente segundo janelas de programação predeterminadas pela radiodifusora; d) a concessionária de radiodifusão é obrigada a transmitir um número de programas gratuitamente, tais como propaganda eleitoral, Hora do Brasil, dentre outros, na televisão ou no rádio, ou informações dos poderes da República no rádio; e) transmissão unidirecional sem interatividade com o canal de retorno, embora esta característica tradicional tenha sido relativizada pela introdução da TV digital terrestre, que permite interatividade e, com isso, torna-se bidirecional; f) há um número mínimo de horas que uma radiodifusora deve transmitir diariamente (art. 38, e, do CBT); g) há um limite máximo de tempo de transmissão de propaganda comercial por canal de programação; h) trata-se de um serviço terrestre; i) trata-se de um serviço de tipo ponto-área, em que todos que se encontrem dentro da área de recepção estão habilitados a receber o sinal; j) a radiodifusora não sabe quem está recebendo o sinal de programação, embora o número de pessoas que recebe o sinal seja conhecido. Esta característica também pode vir a ser atenuada com a interatividade da TV digital; k) o usuário do serviço não necessita de autorização para sê-lo e não precisa pagar para receber o sinal; 1) não há contratos formais entre a radiodifusora e os usuários do serviço; m) os dispositivos de recepção do sinal são baratos e de fácil acesso; n) o consumidor pode escolher o local em que receberá o sinal (isto significa que o consumidor é livre para levar a televisão para sua casa, escritório ou qualquer outro lugar); e o) a propaganda comercial transmitida durante a programação é feita a título oneroso e suportada pelo anunciante.
} 
descortinar: a) toda a mídia eletrônica será regulada do mesmo modo como a radiodifusão é hoje regulada, ou seja, por intermédio de uma abordagem detalhada do regulador; b) as radiodifusoras gozarão de cada vez mais liberdade regulatória usualmente outorgada a seus competidores não radiodifusores: TV a cabo e internet.

Se, por outro lado, a radiodifusão continuar a ser considerada como algo distinto dos outros competidores de conteúdo eletrônico, diferenças significativas de tratamento persistirão no arcabouço regulatório.

A convergência é um dos elementos-chave nesta equação. Se a convergência, de algum modo, elimina as barreiras entre os serviços de radiodifusão e outros meios de comunicação eletrônica - e assim o fez em certa medida -, todas as justificativas para uma regulação assimétrica cairão por terra. Até hoje, todavia, persistem diferenças entre a radiodifusão e outros meios de comunicação eletrônica que justificam uma regulação mais rigorosa sobre a televisão.

Em primeiro lugar, mesmo com a possibilidade tráfego de mais informações em uma mesma faixa de espectro causada pela digitalização, ainda existem muitas questões para serem enfrentadas no que se refere à escassez do espectro. Dois prestadores de serviço de radiodifusão não podem, na mesma frequência, ao mesmo tempo, no mesmo lugar e na mesma direção, transmitir uma programação sem causarem interferência nos seus sinais, ao menos em certa medida. ${ }^{85}$

Em segundo lugar, o modelo para acesso ao conteúdo na radiodifusão é mais difuso, menos controlável e seletivo do que outros meios de comunicação eletrônica. De fato, quando uma pessoa liga sua TV, a possibilidade de restringir o conteúdo é muito mais limitada do que o que ocorre com a internet. Os tribunais norte-americanos decidiram que o conteúdo radiodifusor não é somente difuso, mas também onipresente e produz um impacto subliminar na audiência. ${ }^{86}$

${ }^{85}$ BENJAMIN, Stuart Minor [et al.]. (2006). Telecommunications Law and Policy. Durham, NC: Carolina Academic Press, p. 31.

${ }^{86}$ MITCHELL, William. (2006). The Needle and the Damage Done: The Pervasive Presence of Obsolete Mass Media Audience Models in First Amendment Doctrine. Working Paper 62, p. 49. Vide: http://papers.ssrn.com/sol3/papers.cfm?abstract_id $=945662$.

Revista de Direito, Estado e Telecomunicações, v. 3, n. 1, p. 111-166 (2011)

DOI: https://doi.org/10.26512/lstr.v3i1.21669 
Isso não significa que a regulação de conteúdo tenha que se basear na tecnologia utilizada. Propõe-se, aqui, a regulação de conteúdo desenvolvida pelo professor Eric Knutsen, que defende que a regulação deve ter o que ele chamou de abordagem tecno-neutral [techno-neutral approach]. Tal abordagem se daria por níveis, mediante testes para determinação do campo de abrangência de uma determinada mídia, em que as questões a seguir exigem respostas. Em que contexto a manifestação do pensamento é acessada pelo público? Há justificativa para se diferenciar um meio de comunicação com base no grau de acessibilidade? Existe a possibilidade de se fazerem analogias com base no nível de transferência de informação? A mídia em questão encontra-se em sua forma final ou está em mutação [timelessness factor] ${ }^{87}$

Utilizando-se do teste acima de Knutsen, pode-se concluir que a radiodifusão é essencialmente uma mídia diferenciada, à medida em que ela tem consideravelmente mais difusão, maior grau de transferência e o acesso à radiodifusão ocorre em um contexto menos controlável do que o presenciado na internet. Nos Estados Unidos, quase todos os lares têm TV a cabo ou por satélite e o nível de controle do conteúdo é o mesmo na radiodifusão e na TV a cabo. No Brasil, entretanto, em que a maioria dos lares têm acesso somente a serviços de radiodifusão, as escolhas do consumidor são realmente limitadas.

Assim, a radiodifusão é distinta de outras mídias eletrônicas de informação e, como tal, justifica a assimetria regulatória, devido, em primeiro lugar, às características técnicas citadas acima, neste artigo e, em segundo lugar, às questões de escassez e interferência. Ainda, uma terceira razão para dita distinção está no maior nível de difusão e de transferência da informação na radiodifusão quando em comparação com outras mídias, bem como no contexto específico em que a informação é apresentada ao público.

Esta conclusão, entretanto, é temporária, na medida em que o caráter de imutabilidade [timelessness factor] do modelo de Knutsen não foi ainda detectado no serviço de radiodifusão. Devido a avanços tecnológicos e de convergência, a radiodifusão pode vir a se assemelhar a outros meios de

${ }^{87}$ KNUTSEN, Eric. (2001). Techno-Neutrality of the Freedom of Expression in New Media Beyond Internet: Solutions for the United States and Canada. In: UCLA Entertainment Law Review 8(2). 
comunicação eletrônica. Aplicado ao caso brasileiro, o modelo de Knutsen tende a apoiar a diferenciação existente na Constituição de 1988 entre a radiodifusão e outros serviços e que o PLC 116/2010 visa suprimir. Por isso, o nível de regulação de outras mídias deveria ser menos intenso e rigoroso do que o aplicado à radiodifusão.

O papel da neutralidade de rede e da eficiência do espectro na batalha do conteúdo: status no Brasil

Por último, abordam-se, aqui, as questões pertinentes à neutralidade de rede $^{88}$ no Brasil e os argumentos utilizados para aplicação deste princípio para o fomento de maior pluralismo de fontes de conteúdo eletrônico no país. No debate atual sobre a diversidade de conteúdo, em que o sistema de cotas desempenha um papel importante, existe a proposta de adoção de princípios de neutralidade de rede no contexto brasileiro. As discussões sobre neutralidade de rede no Brasil, entretanto, foram deixadas de fora do PLC 116/2010, muito embora tenham sido levantadas em outros espaços de discussão, como o do marco civil da internet. O princípio de neutralidade de rede pode vir a tornar-se uma ferramenta valiosa para promoção do livre fluxo de informação e para garantia de um maior grau de diversidade de conteúdo eletrônico.

No que diz respeito à questão da eficiência do uso do espectro, a Anatel aprovou, recentemente, a Resolução 548/2010. Entende-se, aqui, que o regulador pode ter agido de forma inadequada para promoção da diversidade e pluralismo de fontes de conteúdo. Nessa resolução, o regulador brasileiro elaborou um modelo para medição da eficiência na alocação de espectro a um prestador de serviço de telecomunicações que distribui conteúdo eletrônico. ${ }^{89}$ Para enfrentar sua percepção de agravamento da escassez do espectro, a Anatel desenvolveu uma fórmula para determinar se um autorizado para uso de espectro utiliza o máximo de capacidade de trânsito

\footnotetext{
${ }^{88} \mathrm{~A}$ neutralidade de rede significa, neste artigo, a característica de uma rede que não privilegia nenhum aplicativo ou conteúdo, representando "uma expressão concreta de um sistema de crenças sobre inovação" (WU, Tim. Network Neutrality, Broadband Discrimination. In: Journal of Telecommunications and High Technology Law 2: 141, 2003).

${ }^{89}$ Resolução do Conselho Diretor da Anatel n. 548, de 8 de novembro de 2010.

Revista de Direito, Estado e Telecomunicações, v. 3, n. 1, p. 111-166 (2011)

DOI: https://doi.org/10.26512/lstr.v3i1.21669
} 
que o espectro alberga. O problema de dita fórmula está no fato de que ela não leva em consideração $o$ formato de transmissão. Em franca desconsideração à qualidade do conteúdo distribuído aos consumidores, a fórmula da Anatel considera ineficiente o uso do espectro pelo autorizado se não forem preenchidas as exigências incorporadas na fórmula. $\mathrm{O}$ que ocorre, contudo, é que a abordagem técnica, por si só, é insuficiente para tratar dos problemas de eficiência do espectro.

A insuficiência da abordagem técnica é comprovada ao se aplicar a seguinte analogia com jornais impressos, ao invés de se utilizar do conteúdo via TV a cabo ou terminais móveis. Alguns anúncios em um jornal impresso seguem o seguinte caminho: eles reservam uma parte da página para uma mensagem impactante de um produto anunciado, deixando o restante da página em branco. Se o anúncio fosse impresso em letras menores, ocupando toda a extensão da página, ele não teria o mesmo impacto. Da mesma forma, um bom poema não precisa ocupar uma página inteira para ser considerado um excelente poema. Livros infantis usam letras maiores e muitos espaços vazios para transmitir sua mensagem de forma mais eficiente do que se as letras fossem pequenas e ocupassem toda a página. Apesar disso, de acordo com a fórmula da Anatel, esse tipo de comunicação seria considerado muito ineficiente. Em outras palavras, uma transmissão pode comunicar uma mensagem genuinamente de qualidade sem fazer uso do espaço total disponível para a transmissão. Não é o montante bruto de bytes em uma transmissão que faz dela uma boa transmissão ou um conteúdo qualificado.

Esse aspecto diferencia as abordagens brasileira e norte-americana de regulação da eficiência do espectro. Ao se avaliar a eficiência do espectro, é necessário levar em conta mais do que aspectos técnicos; também é importante atentar para outros elementos, tais como os aspectos econômicos e sociais. Às vezes, o valor social de uma comunicação supera sua baixa eficiência técnica. A FCC avalia a eficiência do espectro em tais bases, ou seja, levando em consideração um conjunto de fatores técnicos, econômicos e sociais. Ela justifica sua atuação no fato de que o interesse público, às vezes, requer um equilíbrio de interesses: algumas pessoas podem atribuir mais valor a uma ligação de cinco minutos de telefone celular do que a uma hora de televisão ou uma "simples chamada de emergência sobre um canal de segurança pública de uma hora de duração pode superar o valor destes 
outros usos durante o mesmo tempo e ter uma eficiência econômica superior." $" 90$

\section{Conclusão}

A convergência tecnológica é mais do que simplesmente uma teoria, na medida em que tem se tornado gradualmente um roteiro para o futuro dos serviços de telecomunicações. Entre tais serviços, o mercado de vídeo é de fundamental importância, na medida em que ele engloba o reino da manifestação de pensamento. Como ocorre na expressão do mercado de ideias [marketplace of ideas] do juiz Oliver Holmes, da Suprema Corte norte-americana, a liberdade de manifestação do pensamento deveria ser protegida contra quaisquer limitações como um direito natural. ${ }^{91} \mathrm{O}$ mesmo princípio se aplica ao conteúdo eletrônico.

As indústrias de conteúdo eletrônico do Brasil e dos Estados Unidos tiveram modelos semelhantes no início do século XX. Contudo, desde a década de 1960, elas seguiram caminhos diferentes. A análise comparada implementada neste artigo procurou demonstrar, sempre que possível, semelhanças e disparidades entre os dois modelos.

Buscou-se mostrar como o Congresso Nacional e a Agência Nacional de Telecomunicações do Brasil responderam aos desafios e dificuldades por meio de regulação nacional sobre o conteúdo eletrônico. Como alguns dos problemas já foram enfrentados pelos legisladores e reguladores norteamericanos, procurou-se utilizar da experiência norte-americana para compreender-se melhor o estado atual da questões pertinentes no Brasil.

Primeiramente, o artigo introduziu uma definição de convergência e suas principais consequências sobre o desenvolvimento dos serviços de telecomunicações relativos a conteúdo. Em seguida, o artigo partiu de algumas definições de serviços de telecomunicações e verificou que muitas delas não fornecem um parâmetro mínimo para identificação e classificação dos serviços. Após isso, foram exploradas as características regulatórias e técnicas peculiares aos serviços de radiodifusão, cabo e internet. A pesquisa

\footnotetext{
${ }^{90}$ FCC. (2002). Report of the Spectrum Efficiency Working Group. FCC Spectrum Policy Task Force. Vide: http://www.fcc.gov/sptf/files/SEWGFinalReport_1.pdf. ${ }^{91}$ Abrams v. United States, 250 U.S. 616, 629, 40 S.Ct. 17, 22 (1919).

Revista de Direito, Estado e Telecomunicações, v. 3, n. 1, p. 111-166 (2011)

DOI: https://doi.org/10.26512/lstr.v3i1.21669
} 
pôs a descoberto a marcante similaridade entre os modelos regulatórios dos Estados Unidos e do Brasil. A despeito da convergência, ainda persistem significativas diferenças na natureza e características essenciais dos serviços citados. Em um momento seguinte, o artigo procurou contribuir com a formatação de princípios para embasamento de um novo quadro regulatório, em que a convergência pudesse produzir seus efeitos de modo mais eficiente. A academia norte-americana tem produzido uma vasta quantidade de informações úteis para esse fim.

Em seção própria deste artigo, discutiu-se o arcabouço constitucional da indústria de comunicações brasileira e se analisou o papel central desempenhado pela história e pela convergência em dar forma ao comportamento e intenções das radiodifusoras rumo a uma política de conteúdo eletrônico. Por intermédio de um detalhado exame do PLC $116 / 2010$ - a tentativa mais relevante do poder legislativo brasileiro de reforma do panorama regulatório do mercado de vídeo -, o artigo identificou os propósitos e as terríveis consequências da possível aprovação do citado projeto de lei para a indústria de conteúdo eletrônico.

A análise do PLC 116/2010 levou à descoberta dos impactos que o novo modelo regulatório terá, em caso de sua aprovação nos moldes atuais, sobre a internet, as restrições ao investimento estrangeiro na indústria de conteúdo eletrônico e a adoção do sistema de cotas de conteúdo. A aprovação do PLC $116 / 2010$ em sua redação atual seria indevidamente custosa para o modelo de negócios da internet e imporia um ônus que deveria estar reservado somente à seara da radiodifusão. No que se refere ao sistema de cotas de conteúdo, o artigo delineou os vários efeitos negativos que um sistema como este traria para a cadeia de valores do setor de conteúdo eletrônico, bem como trouxe algumas considerações sobre experiências internacionais semelhantes que corroboraram tais inferências.

Mais à frente, o artigo discutiu o papel da neutralidade de redes para atualização do modelo regulatório, permitindo a livre circulação do conteúdo eletrônico. Também defendeu-se que a forma como o princípio de eficiência do espectro têm sido tratado, no Brasil, é equivocada. A adoção de uma abordagem que combine aspectos técnicos, econômicos e sociais, como a que se pratica hoje, nos Estados Unidos, contribuiria para o incremento da produção de conteúdo eletrônico e representaria uma política pública positiva para o Brasil. 
Finalmente, a pesquisa revelou que, apesar dos efeitos irresistíveis da convergência, ainda há várias características peculiares ao serviço de radiodifusão que justificam a adoção da assimetria regulatória. Em comparação com a internet, por exemplo, a radiodifusão é mais espalhada, tem maior grau de transferência e é acessada em um contexto de menor controle por parte do público. Além disso, ela se diferencia devido aos elementos técnicos abordados no texto e a questões de escassez e interferência. Isso é verdade tanto para o Brasil quanto para os Estados Unidos. A mera extensão da atual regulação da radiodifusão no Brasil para a TV a cabo e a internet viria a um alto preço não somente no que toca ao futuro dos negócios, mas também no tocante à liberdade de manifestação do pensamento.

A convergência é uma revolução que reestrutura o entendimento atual, bem como o comportamento da indústria de conteúdo eletrônico. Ela altera os conceitos, derruba barreiras, altera o modo como os serviços são prestados e afeta a arquitetura em que os modelos de negócio estão inseridos. O Brasil está exatamente no meio deste vórtex tecnológico e qualquer ação apressada poderia pôr em jogo a infraestrutura e impedir que o público colha os melhores resultados. $\mathrm{O}$ artigo defende que a extensão ou a simples transposição do austero modelo regulatório da radiodifusão para outras mídias seria uma atitude desarrazoada. Aristóteles afirmou que elementos e partes são incapazes de refletir, de forma convincente, os atributos do gênero a que pertencem..$^{92}$ Quando se leva em consideração a convergência e seus efeitos, a autoridade reguladora e os legisladores deveriam agir cuidadosamente para não retardarem o processo ou, ao mesmo tempo, distendê-lo onde não for necessário.

${ }^{92}$ ARISTÓTELES. Metafísica. Livro VI, 1025b. Porto Alegre: Ed. Globo, 1969.

Revista de Direito, Estado e Telecomunicações, v. 3, n. 1, p. 111-166 (2011)

DOI: https://doi.org/10.26512/lstr.v3i1.21669 


\section{Bibliografia}

ARANHA, M. I. (2005). Políticas públicas comparadas de telecomunicações (Brasil-EUA). Tese de doutorado: CEPPAC/UnB.

BARRON, J. A. (1973). Freedom of the Press for Whom? Right of Access to Mass Media. Bloomington: Indiana University Press.

BARRON, J. A.; DIENES, T. C. (2001). Constitutional Law. St. Paul: West Group.

BENJAMIN, S. M. [et al.] (2006). Telecommunications Law and Policy. Durham, NC: Carolina Academic Press.

BRANDS, H.; LEO, E. T. (1999). The Law and Regulation of Telecommunications Carriers. London: Artech House.

CARTER, T. B.; DEE, J. L.; ZUCKMAN, H. L. (2000). Mass Communications Law. St. Paul: West Group.

CARVALHO, A. A. [et al.]. (2003). Direito da comunicação social. Lisboa: Notícias Editorial.

CASTEllS, M. (2007). A sociedade em rede. A era da informação: economia, sociedade e cultura. São Paulo: Paz e Terra.

CORDOVIL, L. A. G. (2005). A intervenção estatal nas telecomunicações: a visão do direito econômico. Belo Horizonte: Fórum.

DUESTERBERG, T; GORDON, K. (1997). Competition and Regulation in Telecommunications: The Case for a New Paradigm. Indianapolis: Hudson Institute.

FANG, I. (1997). History of Mass Communication: Six Information Revolutions. Boston: Focal Press.

FARRELL, J. [et al.]. (2003). Modularity, Vertical Integration and Open Access Policies: Towards a Convergence of Antitrust and Regulation in the Internet Age. In: Harvard Journal of Law \& Technology 17(1): 86134.

FAUlHABER, G. R. (2005). Bottlenecks and Bandwagons: Access Policy in the New Telecommunications. In: Handbook of Telecommunications and Economics: Technology Evolution and the Internet. Amsterdam: Elsevier North-Holland.

GRANT, A. [et al.]. (2009). Understanding Media Convergence: The State of the Field. New York: Oxford University Press. 
GREENSTEIN, S.; KHANNA, T. (1997). What Does Industry Convergence Means? In: Competing in the Age of Digital Convergence. Boston, MA: Harvard Business School Press.

HALlin, D.; MANCINI, P. (2006). Comparing Media Systems: Three Models of Media and Politics. New York: Cambridge University Press.

JENKINS, H. (2006). Convergence Culture: Where Old and New Media Collide. New York: New York University Press.

JUSTEN FILHO, Marçal. (2002). O direito das agências reguladoras independentes. São Paulo: Dialética.

KATZ, M. [et al.]. (1985). Network Externalities, Competition and Compatibility. In: Am. Econ. Rev. 75: 424.

KENNEDY, Charles H. (2001). An Introduction to US Telecommunications Law. $2^{\mathrm{a}}$ ed., Norwood, MA: Artech House.

KNUTSEN, Eric. (2001). Techno-Neutrality of the Freedom of Expression in New Media Beyond Internet: Solutions for the United States and Canada. In: UCLA Entertainment Law Review 8(2).

KÜNG, L. [et al.]. (2008). The Internet and the Mass Media. Thousand Oaks, CA: Sage Publications.

LAWSON-BORDERS, Gracie. (2005). Media Organizations and Convergence. Routhledge.

LEMLEY, M. (2007). The End-to-End: Preserving the Architecture of the Internet in the Broadband Era. Working Paper 207, Stanford Law School.

LEVY, Jonathan D.; PITSCH, Peter. (1985). Statistical Evidence of Substitutability Among Video Delivery Systems in Video Medias Competition, Regulations, Economics, and Technology. New York: Columbia University Press.

LOETZ, S.; KOENIG, C. Framework for Network Access and Interconnection. In: KOENIG, C. [et. al.]. (2002). EC Competition and Telecommunications Law. Hague: Kluwer Law International.

LOPES, V. M. de O. N. (1997). O direito à informação e as concessões de rádio e televisão. São Paulo: Revista dos Tribunais.

MITCHELL, William. (2006). The Needle and the Damage Done: The Pervasive Presence of Obsolete Mass Media Audience Models in First Amendment Doctrine. Working Paper 62, p. 49. Vide: http://papers.ssrn.com/sol3/papers.cfm?abstract id=945662. 
NEWTON, H. (2002). Newton's Telecom Dictionary. $18^{\mathrm{a}}$ ed., New York: COM Books.

NIHOUL, P.; RODFORD, P. (2004). EU Electronic Communications Law: Competition and Regulation in the European Telecommunications Market. New York: Oxford University Press.

PEREIRA, C. F. de O. (ed.). (2003). O novo direito administratio brasileiro: o Estado, as agências e o terceiro setor. Belo Horizonte: Fórum.

POOL, I. de S. (1983). Technologies of Freedom: On Free Speech on an Electronic Age. Cambridge, MA: Harvard University Press.

PRADO, Paola. (2008). Foreign Ownership of Broadcast Television Stations in the Digital Era. Artigo apresentado no National Communications Association realizado em San Diego, p. 2. Vide: http://www.allacademic.com//meta/p_mla_apa_research_citation/2/5/8/8 /0/pages258802/p258802-1.php.

SHEPERD, Steven. (2002). Telecommunications Convergence: How to

Bridge the Gap Between Technologies and Services. New York: McGraw-Hill Companies.

SMITH, F. L. (1995). Electronic Media and Government: The Regulation of Wireless and Wired Mass Communication in the United States. White Plains, NY: Longman Publisher.

SPARROW, A. (2004). The Law of Internet and Mobile Communications: The EU and US Contrasted: Malta: Gutenberg Press.

SUNSTEIN, Cass. (1995). The First Amendment in Cyberspace. In: Yale Law Journal 104: 1757.

TEETER, Dwight L. [et al.]. (2008). Law of Mass Communications: Freedom and Control of Print and Broadcast Media. New York: Foundation Press.

USTRA, Carlos Alberto Brilhante. (2007). A verdade sufocada. 5a ed., Brasília: Editora Ser.

WALDEN, Ian (ed.). (2009). Telecommunications Law and Regulation. 3ed., Oxford: Oxford University Press.

WU, Tim. (2003). Network Neutrality, Broadband Discrimination. In: Journal of Telecommunications and High Technology Law 2: 141.

YOFFIE, David B. (1997). Competing in the Age of Digital Convergence. Boston: Harvard Business School Press. 
